NIST NSRDS 49

\title{
CYCLE_D: NIST Vapor Compression Cycle Design Program \\ Version 5.1 User's Guide
}

\author{
J.S. Brown \\ P.A. Domanski \\ E.W. Lemmon
}

This publication is available free of charge from:

http://dx.doi.org/10.6028/NIST.NSRDS.49

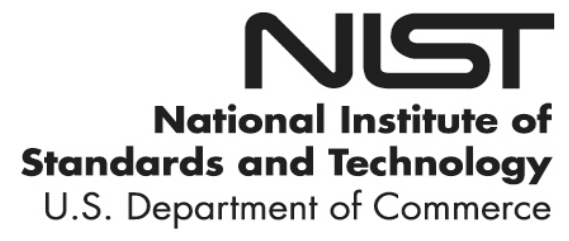


NIST NSRDS 49

\title{
CYCLE_D: NIST Vapor Compression Cycle Design Program \\ Version 5.1 User's Guide
}

\author{
J.S. Brown \\ The Catholic University of America \\ P.A. Domanski \\ Engineering Laboratory \\ E.W. Lemmon \\ Thermophysical Properties Division
}

This publication is available free of charge from:

http://dx.doi.org/10.6028/NIST.NSRDS.49

June 2016

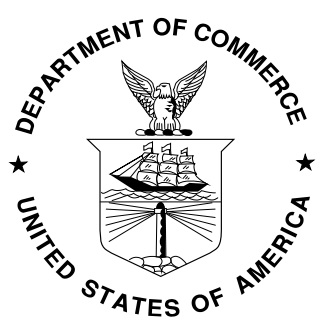

U.S. Department of Commerce

Penny Pritzker, Secretary

National Institute of Standards and Technology Willie May, Under Secretary of Commerce for Standards and Technology and Director 
The National Institute of Standards and Technology (NIST) uses its best efforts to deliver a high quality copy of the Database and to verify that the data contained therein have been selected on the basis of sound scientific judgment. However, NIST makes no warranties to that effect, and NIST shall not be liable for any damage that may result from errors or omissions in the Database.

NIST Standard Reference Database 23 -(c) 1989, 1991, 1993, 1998, 2003, 2009, 2010, 2012, 2016 copyright by the U.S. Secretary of Commerce on behalf of the United States of America. All rights reserved. No part of this database may be reproduced, stored in a retrieval system, or transmitted, in any form or by any means, electronic, mechanical, photocopying, recording, or otherwise, without the prior written permission of the distributor.

Certain trade names and company products are mentioned in the text to specify adequately the computer products and equipment needed to use this software. In no case does such identification imply endorsement or recommendation by the National Institute of Standards and Technology of these computer products and equipment, nor does it imply that the products are necessarily the best available for the purpose.

Microsoft is a registered trademark, and Windows is a trademark of the Microsoft Corporation. All other brand and product names are trademarks or registered trademarks of their respective companies. 


\section{ACKNOWLEDGMENTS}

Version 1.0 of CYCLE_D, authored by J. Chi, D.A. Didion, and P.A. Domanski, was developed in 1992 under partial funding from the Trane Company and the Electric Power Research Institute, with G. Lange and T. Statt managing the project. The authors acknowledge helpful suggestions from P. Glamm. J. Wnek made modifications and improvements of the graphical user interface in Version 2.0, and J. Schnotale and P.A. Domanski implemented thermodynamic charts and line sizing calculations in Version 3.0. For Version 4.0, J. S. Brown extended simulation options to include transcritical cycles, cycles with two-stage compression with intercooling, and two and three-stage economizer cycles; and E. W. Lemmon provided new thermodynamic charts. The authors acknowledge $\mathrm{K}$. Tchen's assistance in upgrading the graphical user interface, and J. Calm, D. Yashar, B. Dougherty, and T. Watson for their testing and comments on the program. For Version 5.0, J. S. Brown upgraded property calculation routines to REFPROP 9.0 and made the following program modifications: (1) allow for saturation pressure inputs for both the evaporator and the condenser, (2) allow the user to impose refrigerant pressure drops in the evaporator and in the condenser, (3) allow the user to specify the compressor isentropic efficiency for each stage for multistage cycles, (4) allow the user to assign waste heat from motor inefficiency losses to either the evaporator load, suction refrigerant vapor, or condenser load, and (5) allow for the optimization of the intermediate pressures for a three-stage economizer cycle. Version 5.1 implements REFPROP 9.1 refrigerant property routines and several new singlecomponent and blend refrigerants. 
This publication is available free of charge from http://dx.doi.org/10.6028/NIST.NSRDS.49

\section{CONTENTS}

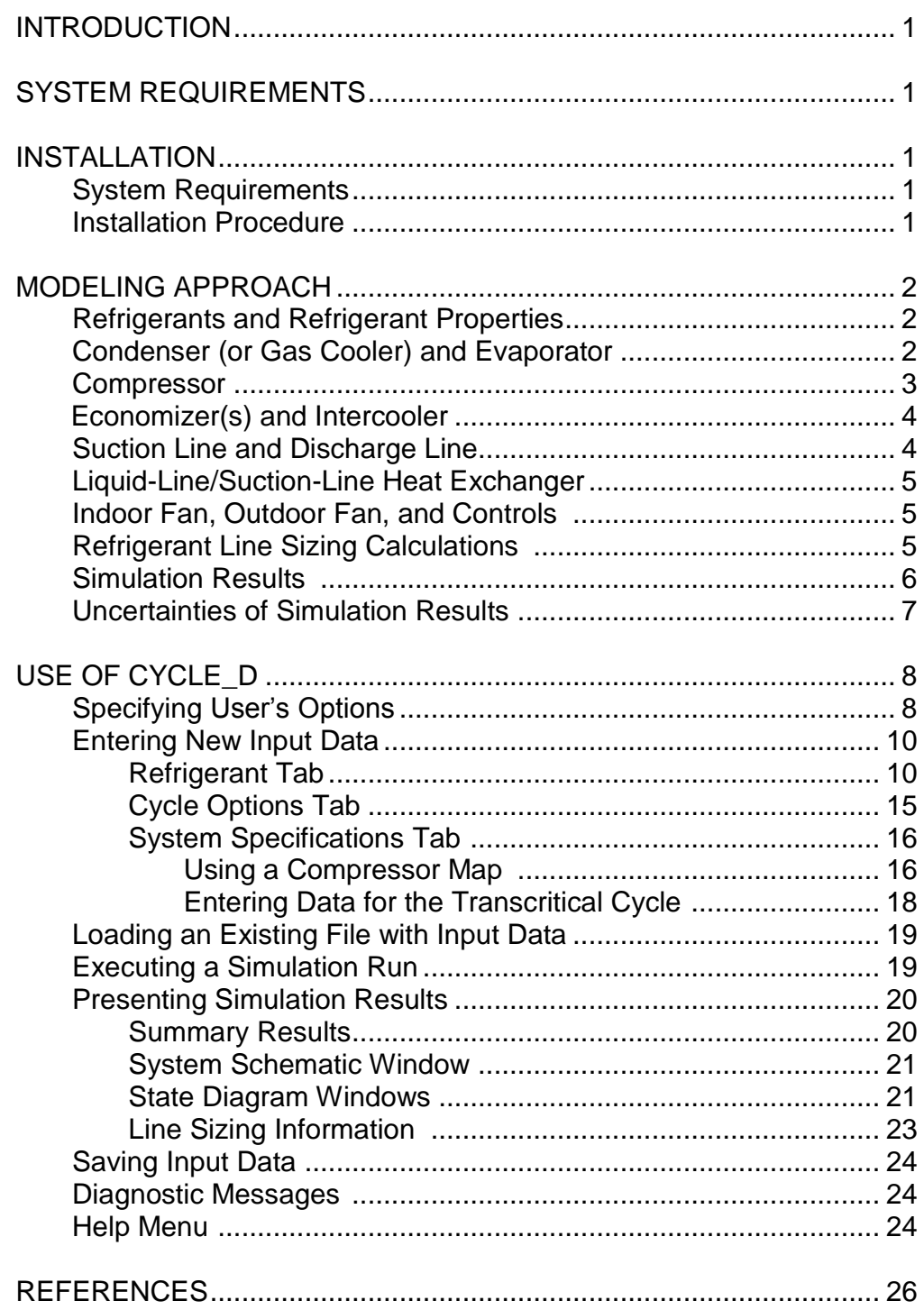


This publication is available free of charge from http://dx.doi.org/10.6028/NIST.NSRDS.49

Appendix A. SINGLE-COMPOUND REFRIGERANTS

AVAILABLE IN CYCLE_D .......................................... 27

Appendix B. PREDEFINED REFRIGERANT BLENDS

AVAILABLE IN CYCLE_D ......................................... 29

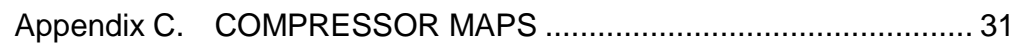

Compressor Map Formats......................................... 31

Preparing a New Compressor Map ............................... 32

Appendix D. NOMENCLATURE USED FOR REPORTING

SIMULATION RESULTS ............................................... 34

Appendix E. UNITS, CHECKS AND WARNINGS ……………........ 35

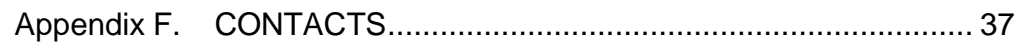




\section{INTRODUCTION}

The CYCLE_D package simulates vapor compression refrigeration cycles that use pure refrigerants or blends of refrigerants. The model can simulate a basic subcritical or transcritical refrigeration cycle, both with or without a liquid-line/suction-line heat exchanger. In addition, the model can simulate a subcritical two-stage economizer cycle, a subcritical three-stage economizer cycle, and a subcritical two-stage compression cycle with intercooling. CYCLE_D operates in a Microsoft Windows environment that facilitates evaluating the performance of selected working fluids at different operating conditions. Calculations are based on refrigerant properties as represented in the NIST Reference Fluid Thermodynamic and Transport Properties Program - REFPROP, Version 9.1 [1].

\section{INSTALLATION}

\section{System Requirements}

Personal computer capable of running Microsoft ${ }^{\circledR}$ Windows $^{\mathrm{TM}} 7,8,10$, or $\mathrm{XP}$ with Service Pack 3. A hard disk with eight megabytes of available space is required. The screen resolution should be set to $800 \times 600$ or higher to view images in their entirety.

\section{Installation Procedure}

Execute the CYCLE_D installation file setup.exe with CYCLE_D Setup.msi residing in the same directory. Follow the installation instructions. A NIST CYCLE_D Program Group will be created at the end of the installation.

To run the program, double-click on the NIST CYCLE_D icon. 


\section{MODELING APPROACH}

The basic subcritical or transcritical system simulated by CYCLE_D consists of a compressor, a discharge line, a condenser for the subcritical cycle (a gas cooler for the transcritical cycle), an expansion device, an evaporator, a compressor suction line, and an optional liquid-line/suctionline heat exchanger. The other subcritical cycles may contain a second compressor, one or two economizers, or an intercooler. These other subcritical cycles, however, do not include the optional liquid-line/suctionline heat exchanger. The user of the program has to specify the refrigerant and provide input data for the above hardware components, except the expansion device, which is modeled as being isenthalpic. The user can also specify the power requirements of the indoor fan, outdoor fan, and control unit of the system.

\section{Refrigerants and Refrigerant Properties}

CYCLE_D includes 70 single-compound refrigerants, which can be selected as the working fluid. These pure refrigerants can also be combined to form blends of up to five components. In addition, CYCLE_D includes 97 predefined mixtures. See Appendix A for the list of available pure refrigerants and Appendix $B$ for the list of available predefined mixtures.

CYCLE_D uses REFPROP 9.1 [1] routines for calculating thermodynamic properties of pure refrigerants and refrigerant mixtures and applies the default models recommended in REFPROP for property predictions.

\section{Evaporator and Condenser or Gas Cooler}

The evaporator and condenser are represented by specifying the refrigerant temperature (or pressure) in each of these heat exchangers.

The refrigerant temperature (or pressure) in the evaporator can be specified as either a dew-point temperature (or pressure) or an average temperature (or pressure). The average temperature (or pressure) in the evaporator is calculated as an arithmetic mean of the dew-point temperature (or pressure) and the temperature (or pressure) of the refrigerant entering the evaporator. Additionally, the refrigerant superheat at the evaporator exit can be specified.

The refrigerant temperature (or pressure) in the condenser can be specified to be either a bubble-point temperature (or pressure), a dew-point temperature (or pressure), or an average temperature (or pressure). The average temperature (or pressure) is calculated as an arithmetic mean of the dew-point and bubble-point temperatures (pressures). Additionally, refrigerant subcooling at the condenser outlet can be specified.

\section{CYCLE_D 2}


In addition to specifying refrigerant saturation temperature (or pressure), the user may specify a refrigerant pressure drop (or saturation temperature drop) for the evaporator and/or the condenser. The program assigns the entire pressure drop to the two-phase refrigerant.

The gas cooler is represented either by specifying the refrigerant pressure or allowing the program to optimize the refrigerant pressure, and specifying the refrigerant exit temperature. Zero pressure drop is assumed in the gas cooler. The gas cooler pressure can be either specified or optimized by the program for the maximum coefficient of performance.

The use of an average temperature (or pressure) in the condenser and evaporator as a mean of refrigerant temperatures (or pressures) at the end of two-phase processes is a simplification because temperature profile versus enthalpy in a two-phase region is not linear, in particular for largeglide zeotropic mixtures.

\section{Compressor}

For a basic subcritical cycle, CYCLE_D provides two options for representation of the compressor: the "Compressor Efficiency" option and the "Compressor Map" option. For other subcritical cycles and for the transcritical cycle, only the "Compressor Efficiency" option is available.

The "Compressor Efficiency" option requires input values of isentropic efficiency, compressor volumetric efficiency, electric-motor efficiency, and a target system Cooling Capacity, which is the evaporator capacity adjusted for the heat added by the indoor coil fan. If the compression process occurs in stages, the isentropic efficiency for each stage can be independently specified. If the cycle includes two compressors, their inputs have to be independently specified.

If the value used for the electric motor efficiency is less than unity, the entire heat rejected by the electric motor(s) can be assigned: (1) as an extra evaporator load reducing the capacity available for cooling duty, (2) as heat superheating the suction vapor within a hermetic compressor shell before the compressor's cylinder inlet, or (3) as an extra condenser load in a system with a liquid pump, which pumps the liquid refrigerant from the condenser outlet to cool the motor and returns the refrigerant to the condenser inlet.

The "Compressor Map" option uses compressor-map correlations, which are typically derived from compressor calorimeter tests. Three types of correlations are allowed. They are described in Appendix C.

CYCLE_D 3 
The "Compressor Map" option also requires a value for either the system Cooling Capacity or Capacity Multiplier. If Capacity Multiplier is specified, its value is used in the simulation as a multiplication factor for compressor capacity (calculated by compressor-map correlations) and for indoor and outdoor fan powers (entered by the user). Power input to the system control unit is unaffected. If the system Cooling Capacity is specified, the simulations are performed for a system with a compressor of identical efficiency characteristics but with adjusted displacement, so that the system can provide the specified capacity. The power input to the indoor and outdoor fans and system control unit are unaffected by the specified capacity value.

Compressor-map equations correlate the compressor performance at certain values of the suction superheat and condenser subcooling. To allow simulations at user-specified conditions, the following steps and assumptions are employed by the model:

- The isentropic efficiency of the compressor is calculated using the compressor-map correlations at user-specified saturation temperatures (or pressures) and at the superheat and subcooling levels used during the calorimeter tests. It is assumed that the isentropic efficiency is not affected by the level of superheat, and the calculated efficiency value is used in the cycle calculations.

- When calculating the refrigerant mass flow rate, it is assumed that the compressor volumetric efficiency and speed (revolutions per minute, RPM) are not affected by the suction vapor superheat. Consequently, the refrigerant mass flow rate at the user-specified superheat equals the value of mass flow rate at the superheat set during the calorimeter tests, adjusted for the different specific volume of the suction vapor caused by a different superheat.

\section{Economizer(s) and Intercooler}

The economizers and intercooler are represented by the refrigerant pressures for these intermediate components. For the economizer cycles, the user can specify the intermediate pressures or have them optimized by the program for the maximum coefficient of performance.

\section{Suction Line and Discharge Line}

The pressure drop in the suction and discharge lines can be specified by assigning a value of the corresponding saturation temperature drop of the refrigerant. CYCLE_D assumes the lines are adiabatic.

\section{CYCLE_D 4}




\section{Liquid-Line/Suction-Line Heat Exchanger}

The liquid-line/suction-line heat exchanger (LLSL-HX) is specified by the user by assigning an effectiveness value of the heat exchanger. The assignment of zero effectiveness denotes no LLSL-HX in the cycle.

\section{Indoor Fan, Outdoor Fan, and Controls}

The auxiliary powers are specified by the user. The indoor and outdoor fan powers are used in the total power calculation and as heat in the capacity calculations for the evaporator and condenser. The control unit power is only used in the total power calculation.

\section{Refrigerant Line Sizing Calculations}

After cycle calculations have been completed, CYCLE_D can provide sizing information for the compressor suction and discharge lines and for the liquid line connecting the condenser and expansion valve. This information includes refrigerant velocity and tube lengths for a range of diameters of straight type $L$ copper tubing.

CYCLE_D calculates refrigerant velocity and tube length using refrigerant state parameters and the mass flow rate determined during cycle simulations, and the predetermined pressure drop in the refrigerant lines. For the suction and discharge lines, the pressure drops are those specified by the user in the System Specifications tab in terms of the refrigerant dew-point temperature drop. For the liquid line, CYCLE_D calculates the line length for the pressure drop that would result in bringing the subcooled refrigerant to flashing. The refrigerant tube length is calculated by the following equation:

$L=2 \cdot \Delta P \cdot D \cdot \rho /\left(f \cdot G^{2}\right)$

where:

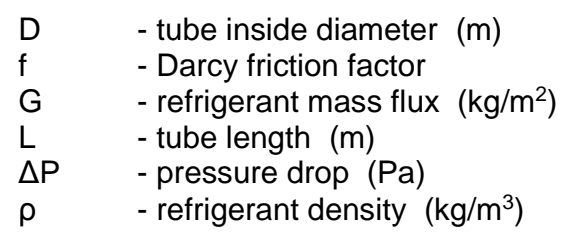

For the Reynolds number $(R e)$ less than 2000 , the friction factor $f=64 / R e$ for fully developed laminar flow is used [3], and the Petukhov's correlation for friction factor for turbulent flow, $f=1 /(1.58 \cdot \ln (\operatorname{Re})-3.28)^{2}[4]$, is used for higher Reynolds numbers. The calculations assume lubricant-free refrigerant

CYCLE_D 5 
flowing in adiabatic tubes, and use refrigerant parameters corresponding to the average of the inlet and outlet pressures.

The refrigerant velocity values presented by CYCLE_D are those at tube inlets. Refrigerant velocity varies in a tube because of a pressure drop and change of specific volume. The lowest velocity, critical to oil return, is at the tube inlet because of the lowest specific volume.

The program does not provide line length values for zero pressure drops; i.e., for zero condenser subcooling for the liquid line, and for zero drop in saturation temperatures for the vapor lines. Also, the program does not provide results for the liquid and suction lines if the system employs a liquid-line/suction-line heat exchanger.

Note that CYCLE_D performs refrigerant line sizing calculations using several simplifications. The line sizing information is provided by CYCLE_D for general orientation and should not be used as strict design criteria for field application.

\section{Simulation Results}

Simulation results are generated in two categories: (1) for the thermodynamic cycle and (2) for the compressor and system. The cycle category presents the results obtained per unit mass of refrigerant circulated by the compressor. These results reflect refrigerant parameters only and are not affected by the auxiliary power input to the indoor fan, outdoor fan, and controls.

If the electric motor efficiency is less than unity, the user's allocation of the waste heat will affect the simulation results. The waste heat is calculated by the following equation:

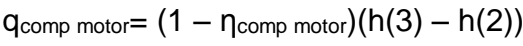

where:

qcomp motor - compressor motor waste heat $(\mathrm{kJ} / \mathrm{kg})$

ncomp motor - compressor motor efficiency (fraction)

$h(3)$ and $h(2)$ - refrigerant enthalpy at the cylinder outlet and inlet, respectively $(\mathrm{kJ} / \mathrm{kg})$

(Refer to page 20 for the Summary Results window.)

Allocation of the waste heat as an extra evaporator load directly reduces the cooling capacity provided by the evaporator to its environment by the amount of the waste heat. Allocation of the waste heat as an extra condenser load directly increases the heating capacity provided by the condenser to its environment by the amount of the waste heat. In this case, cooling of the electric motor is implemented with the refrigerant pumped by

\section{CYCLE_D 6}


a liquid pump from the condenser outlet to the motor, and then returned to the condenser inlet. The flow rate of the refrigerant pumped by the liquid pump is controlled so the refrigerant enthalpy after absorbing heat from the electric motor equals the enthalpy of refrigerant at the compressor outlet.

The allocation of waste heat as an extra evaporator or condenser load does not alter the state parameters of the thermodynamic cycle because cycle simulations are constrained by the specified saturation temperature (pressure) for the evaporator and the saturation temperature (pressure) and subcooling for the condenser. However, the state parameters of the thermodynamic cycle are altered by allocating the waste heat to the suction vapor, which increases refrigerant temperature at the cylinder inlet.

The compressor and system results are calculated for the system based on the Cooling Capacity or Capacity Multiplier specified by the user. CYCLE_D calculates line sizing information using the thermodynamic parameters identified throughout the cycle and the refrigerant mass flow rate needed to obtain the target system capacity. The naming convention used for simulation results is explained in Appendix D.

\section{Uncertainties in Simulation Results}

Uncertainties in the simulation results are directly related to the uncertainties of thermodynamic properties calculated by REFPROP 9.1 [1] routines incorporated into the CYCLE_D package. CYCLE_D uses the REFPROP default property models, which should provide the most accurate predictions. The user should be aware that the uncertainties in these models vary somewhat depending on the refrigerant, property, and thermodynamic state. It is thus impossible to give a simple, global statement of uncertainties. Even for the most-studied fluids with equations of state based on accurate, wide-ranging data, uncertainties are complicated functions of temperature and pressure. For details, refer to the original literature sources listed in [1]. 


\section{USE OF CYCLE_D}

This section explains how to use CYCLE_D: to specify a cycle/system; how to run a simulation; to present simulation results; and to manage input/output files. If the user needs additional information after going through this tutorial, he or she may refer to CYCLE_D's Help menu.

Once CYCLE_D is installed on your computer, it can be started by double clicking on the CYCLE_D icon. The opening screen is displayed first. Click on the OK button to proceed. After doing so, the main CYCLE_D screen appears. Figure 1 shows the main screen after a new session has been started and the user has clicked on the 'Options' pull down menu.

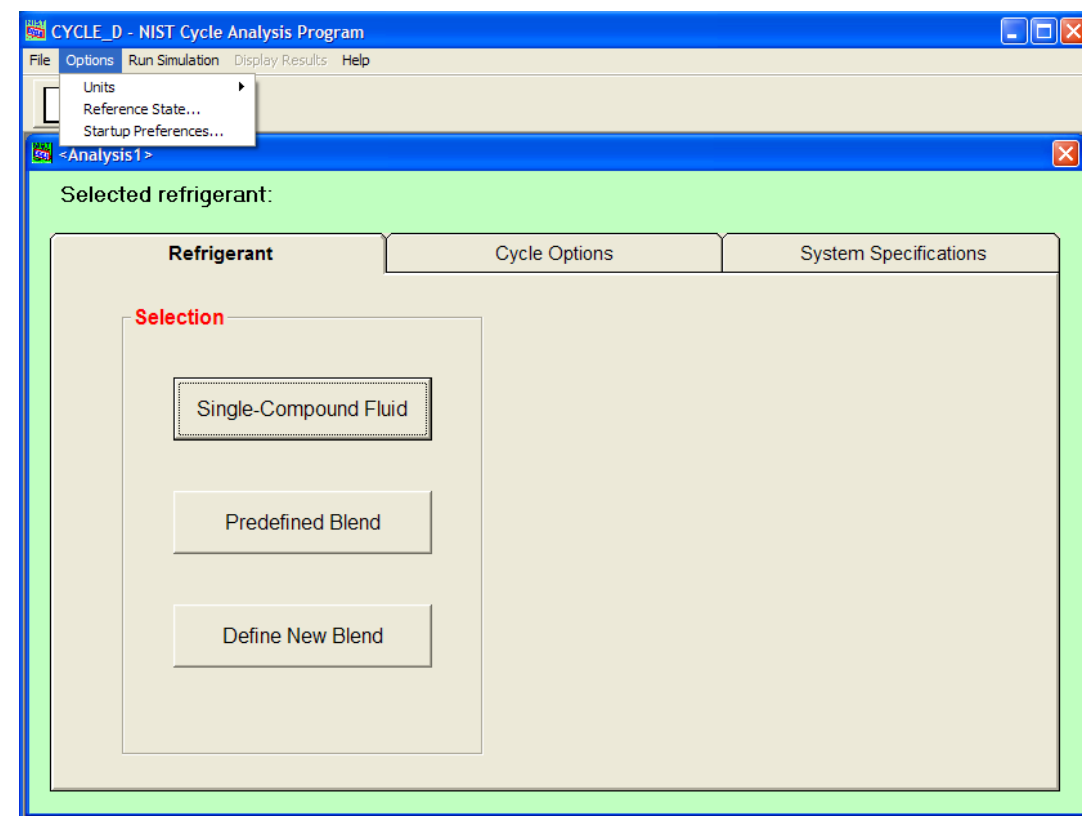

Figure 1. Main window with activated Options pulldown menu

\section{Specifying User's Options}

To select either SI or Inch-Pound (I-P) units, click the Options/Units menu item. There are three options for units: (1) SI with temperatures specified in $\mathrm{K}$, (2) SI with temperatures specified in ${ }^{\circ} \mathrm{C}$, or (3) I-P with temperatures specified in ${ }^{\circ} \mathrm{F}$.

\section{CYCLE_D 8}


To select the reference state for enthalpy and entropy calculations [1], click on the Options/Reference State menu item, after which Figure 2 appears. Note: the reference states are completely arbitrary; however, three common ones are provided: (1) setting enthalpy and entropy values to zero at the selected refrigerant's normal boiling point, (2) ASHRAE convention, or (3) International Institute of Refrigeration (IIR) convention. The first radio button option, if selected, uses the REFPROP 9.1 [1] default reference state for that particular refrigerant. If a blend is selected, the reference state is applied to the blend and not to each pure component.

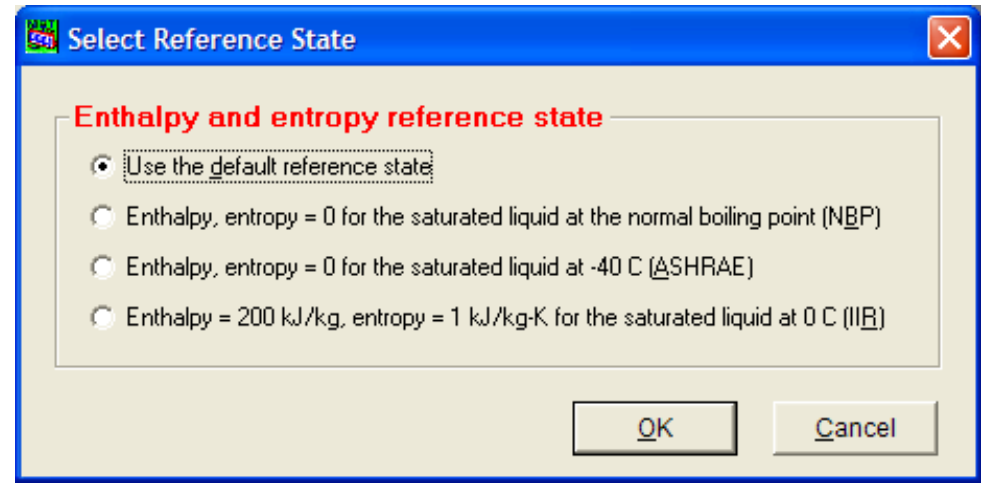

Figure 2. Selecting reference state for enthalpy and entropy calculations

Figure 3 shows the choices for Startup Preferences. When the user sets the option to load an initial file (which could be the last file used or a default file), the units and reference state preferences stored in that file become the current preferences for a given session. If desired, these preferences can be changed manually using the Options pulldown menu. Note that loading any existing file anytime during a simulation session will change the current preferences for this session to those stored in the loaded file. 


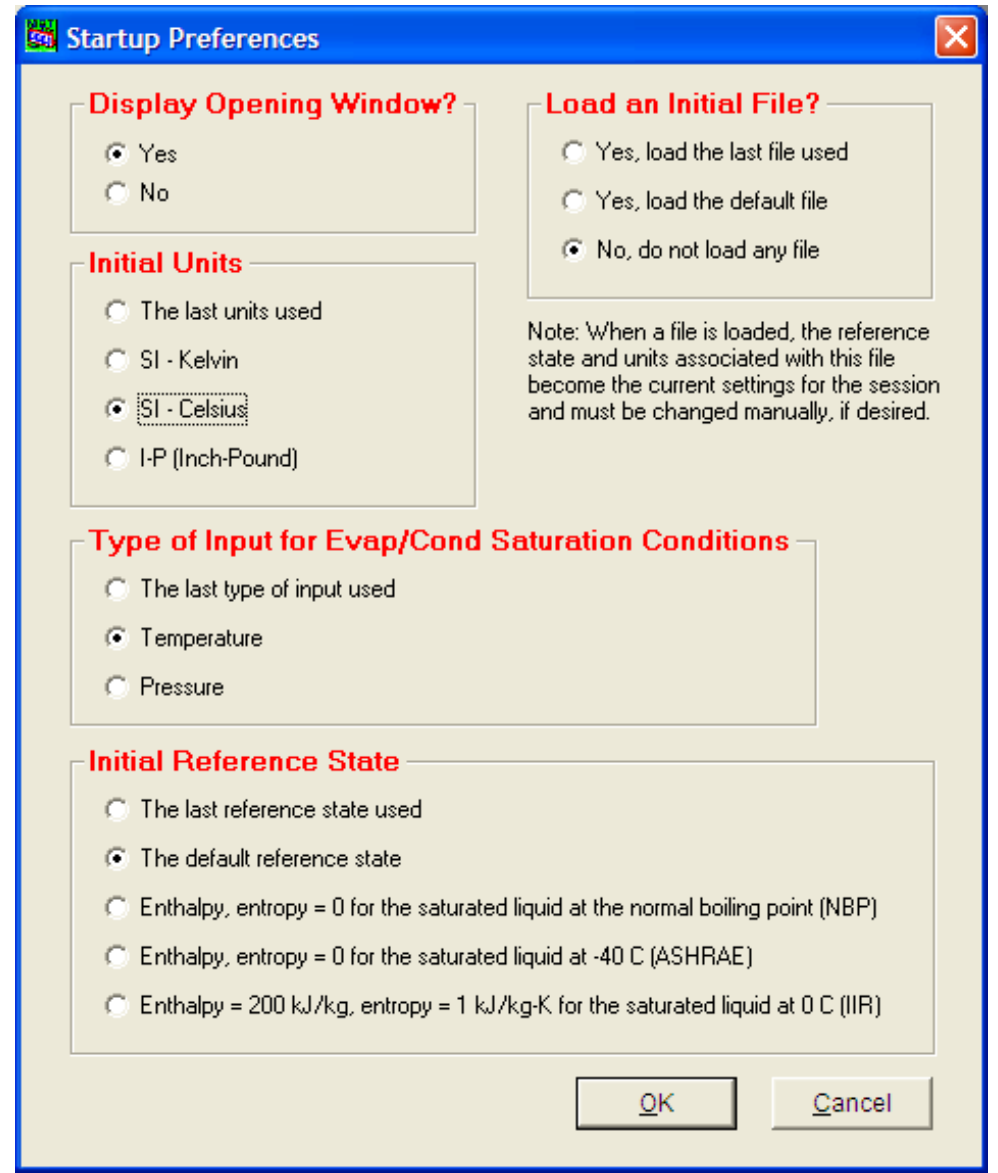

Figure 3. Startup Preferences

\section{Entering New Input Data}

To enter new data, the user needs to use the three tabs titled Refrigerant, Cycle Options, and System Specifications shown in Figure 1. The sequence of using these tabs does not matter.

\section{$\underline{\text { Refrigerant Tab }}$}

The Refrigerant tab provides three options: (1) Single-Compound Fluid (Figure 4), (2) Predefined Blend (Figure 6), and (3) Define New Blend (Figure 8).

\section{CYCLE_D 10}




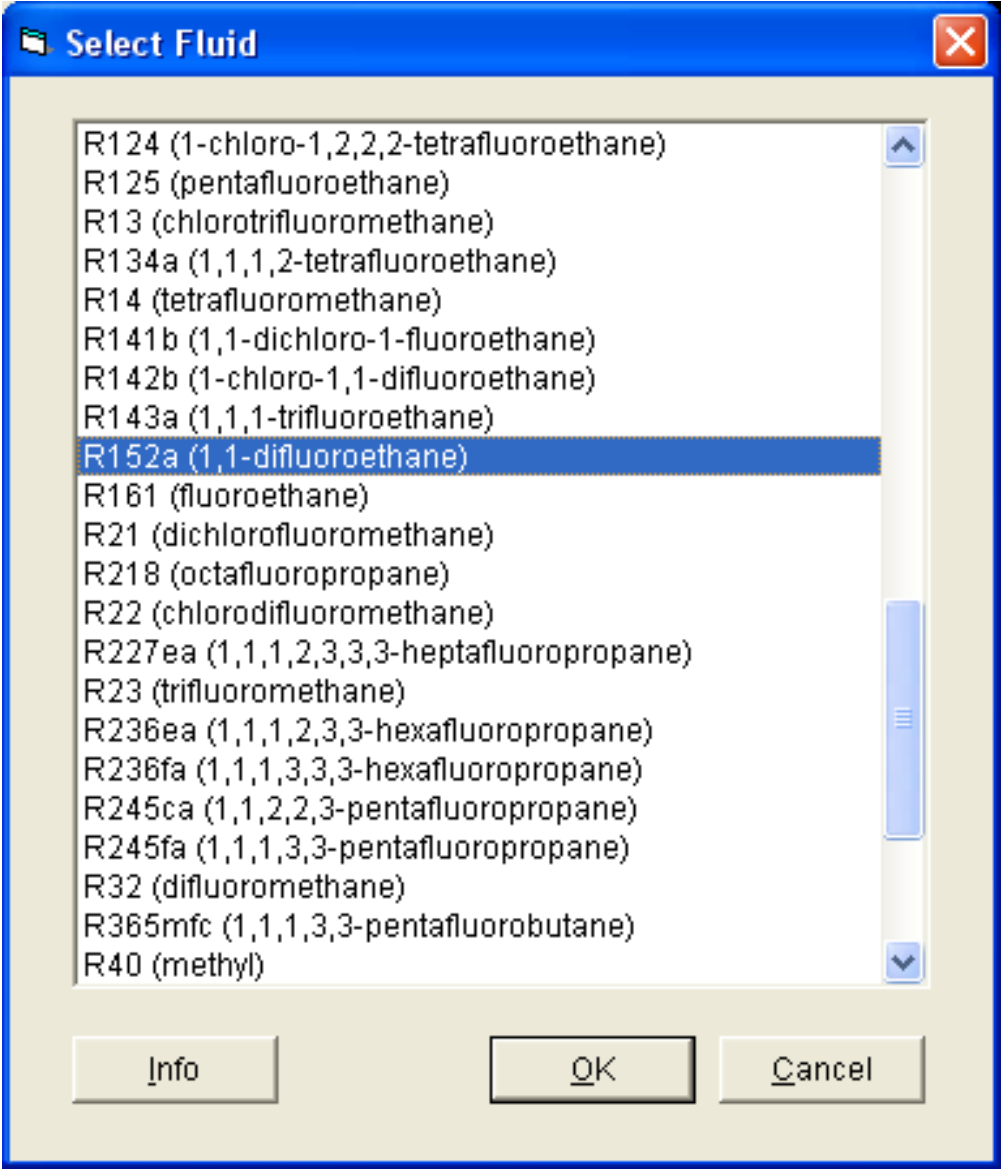

Figure 4. Selecting a single-compound fluid

The user may click the Info button, shown in Figures 4 and 6, to display information for the selected refrigerant, examples of which are shown in Figures 5 and 7 for a single-compound fluid and predefined blend, respectively. 
This publication is available free of charge from http://dx.doi.org/10.6028/NIST.NSRDS.49

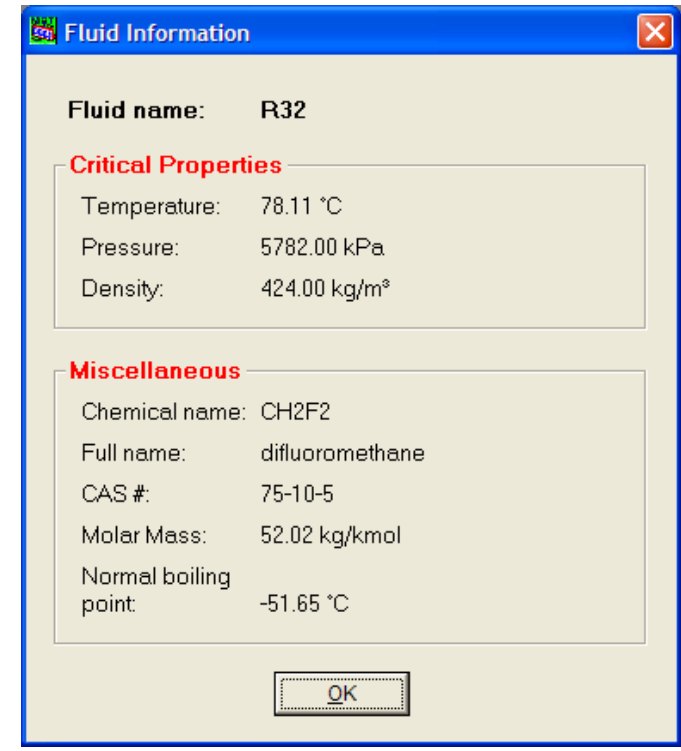

Figure 5. Information for a single-compound fluid

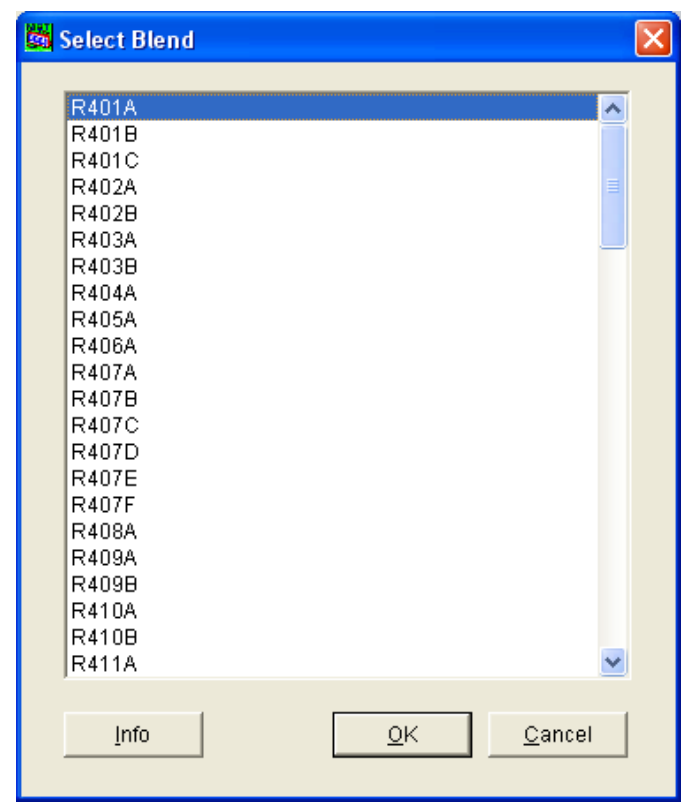

Figure 6. Selecting a predefined blend

\section{CYCLE_D 12}




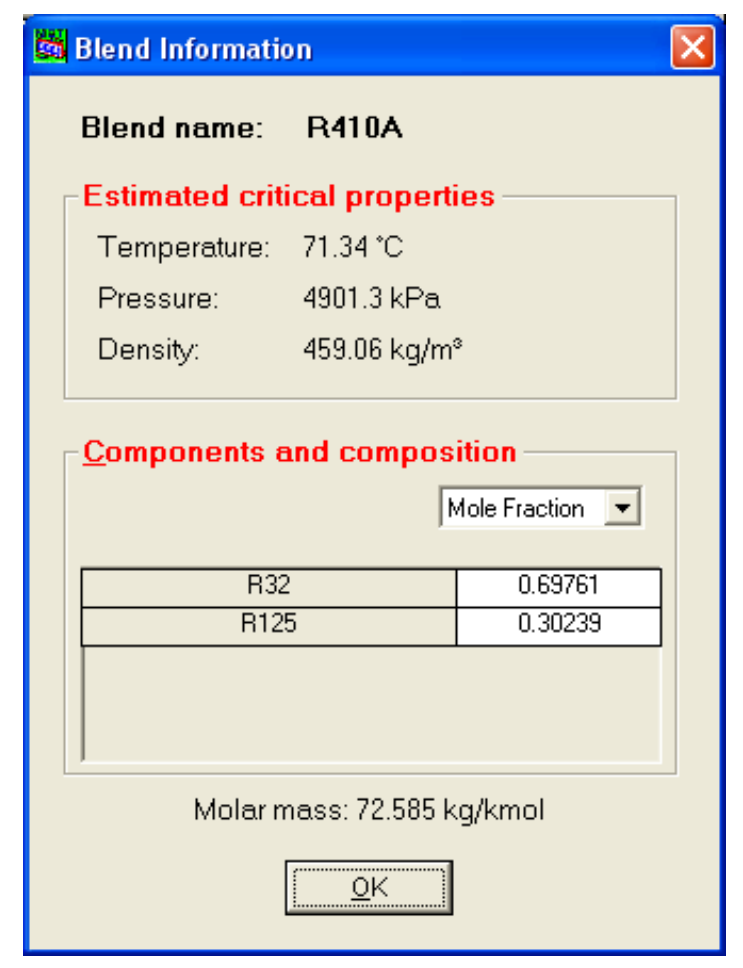

Figure 7. Information for a predefined blend

For the Define New Blend option (Figure 8), refrigerants from the left-hand list can be added to the mixture (right-hand list) via the Add button. Refrigerants can be deleted from the mixture by using the Remove button. After specifying the mixture and clicking OK, Figure 9 appears. The composition can be modified by typing the appropriate values in the boxes and clicking OK. The composition can be specified in terms of mass fractions or mole fractions by toggling the combo box. Note: the mass and mole fractions must sum to unity; if they do not, an error message will appear. The new mixture can be stored by clicking the Store button. If the mixture is stored in the " $\sim$ mixtures" subdirectory, it will thereafter appear in the list of predefined mixtures (Figure 6). 
This publication is available free of charge from http://dx.doi.org/10.6028/NIST.NSRDS.49

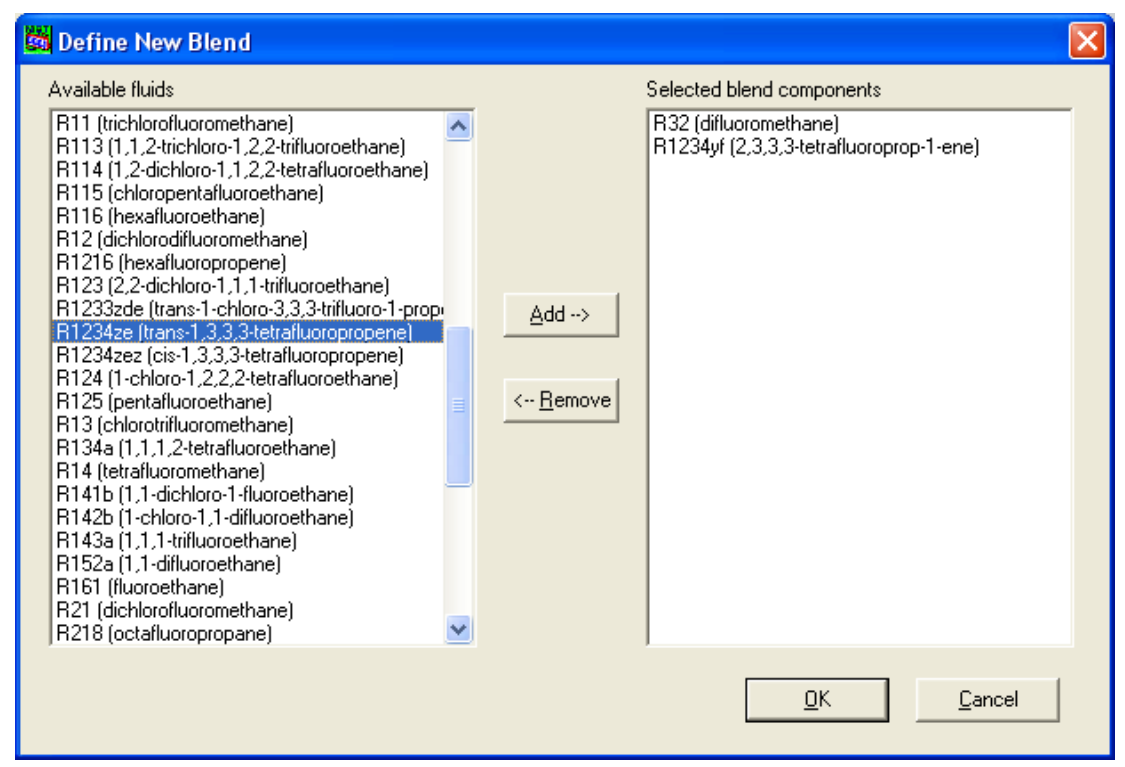

Figure 8. Defining a new blend

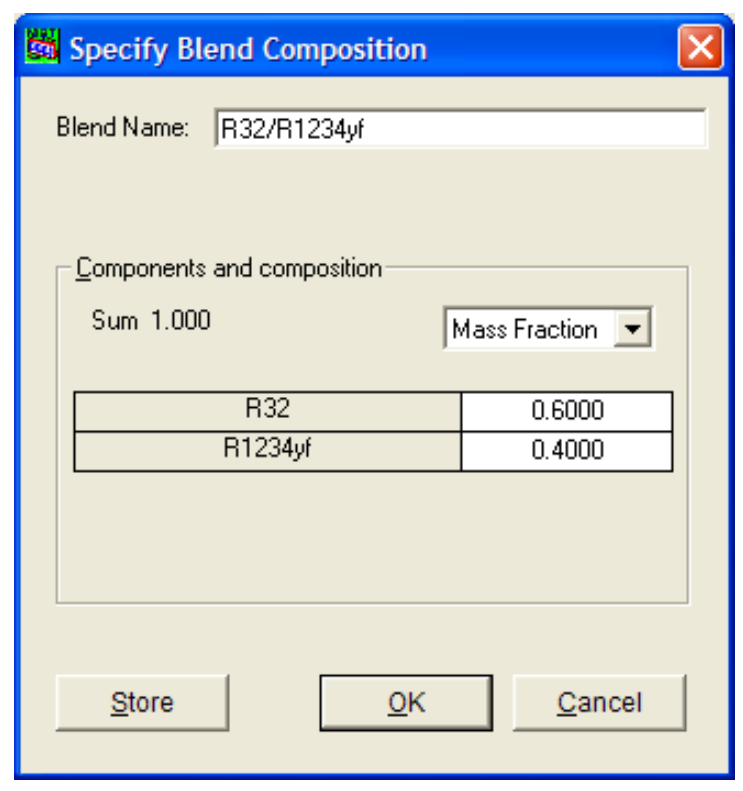

Figure 9. Specifying the new blend composition

\section{CYCLE_D 14}




\section{Cycle Options Tab}

The Cycle Options tab presents the following cycle choices (Figure 10):

- Single-stage cycle with or without a LLSL-HX

- Two-stage cycle with an economizer, which includes an option to optimize the intermediate pressure

- Two-stage cycle with an intercooler

- Three-stage cycle with an economizer, which includes an option to optimize the intermediate pressure.

In the example shown in Figure 10, we selected the single-stage cycle with the LLSL-HX of $50 \%$ effectiveness.

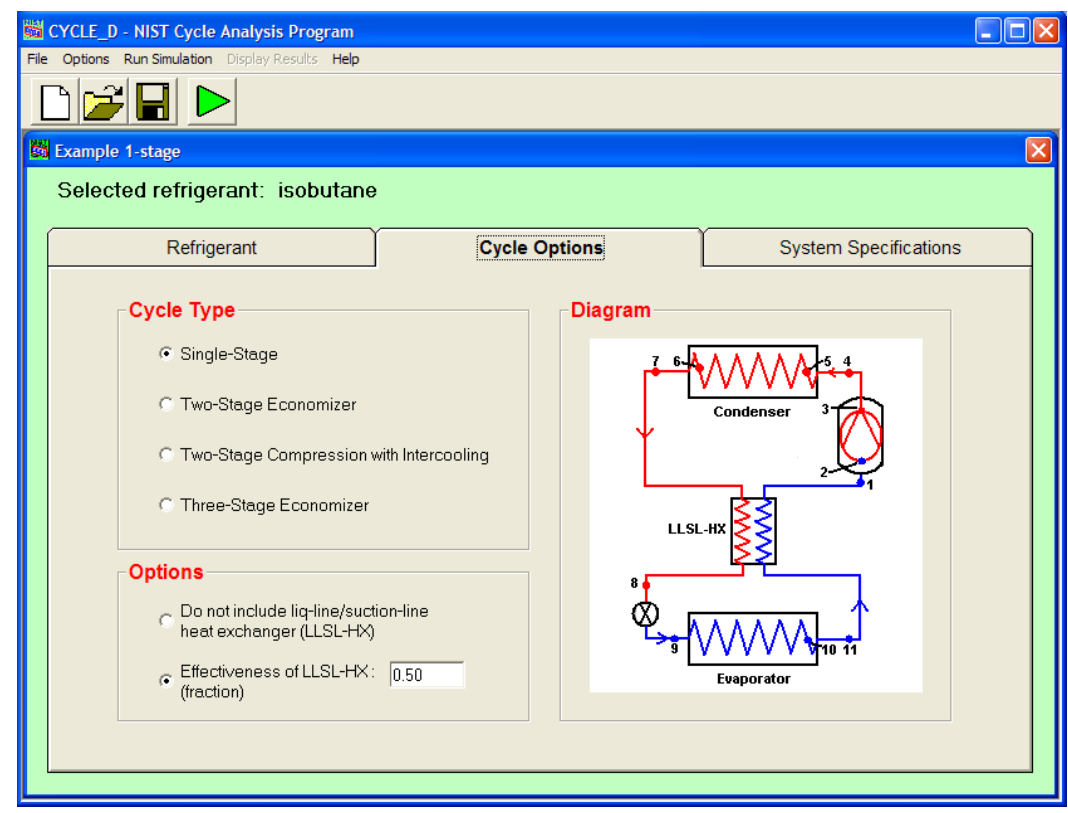

Figure 10. Cycle Options tab

For two-stage economizer cycles, click the Two-Stage Economizer radio button and then click either the Impose intermediate pressure radio button or the Optimize intermediate pressure radio button, and either the Impose same efficiencies for both stages radio button or the Specify different efficiencies for the two stages radio button. The Cycle Options tab will display these options after the Two-Stage Economizer option has been selected. 
For two-stage compression with intercooling cycles, click the Two-Stage Compression with Intercooling radio button and then input the Intermediate pressure.

For three-stage economizer cycles, click the Three-Stage Economizer radio button and then click either the Intermediate pressure for highpressure stage radio button and the Intermediate pressure for lowpressure stage radio button or the Optimize the intermediate pressures radio button, and for both compressors either Impose same efficiencies for both stages radio button or Specify different efficiencies for the two stages radio button; the Cycle Options tab will display these options after the Three-Stage Economizer option has been selected.

\section{System Specifications Tab}

The set of data required for the system specification depends on the simulated cycle type. Figure 11 presents the specification input for a singlestage system operating in a subcritical regime. In this example, specify the compressor by inputting the compressor isentropic efficiency, compressor volumetric efficiency, and compressor electric motor efficiency, all expressed in fractions. The right-hand-side column includes the net system Cooling Capacity, Vapor Line Pressure Drop in terms of a drop of dewpoint temperature, and Auxiliary Power input.

The gas cooler (transcritical cycle) and compressor maps options shown in Figure 11 are only available for the single-stage, subcritical cycle selected in this example. For multi-stage cycles the System Specifications tab will solicit input for intermediate pressure(s), which is not applicable to the single-stage system.

\section{Using a Compressor Map}

The compressor map option is available for a basic subcritical cycle. When the Switch to Maps button is clicked, the System Specifications window will allow the user to select a compressor from the pulldown menu located in the Compressor box, as shown in Figure 12. Once a compressor is chosen, the user needs to select either the system Cooling Capacity or Capacity Multiplier option. For simulating a system with a capacity provided by the selected compressor, input the value 1 in the Capacity Multiplier input box.

Appendix $\mathrm{C}$ explains how to input a new or modify an existing compressor map.

\section{CYCLE_D 16}


This publication is available free of charge from http://dx.doi.org/10.6028/NIST.NSRDS.49

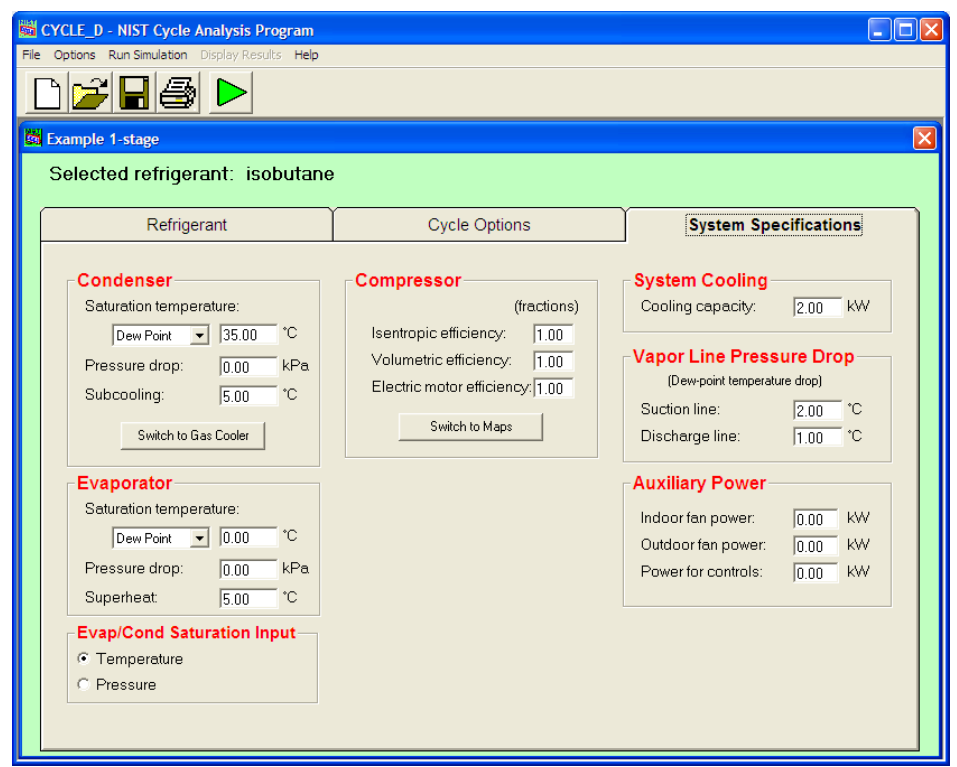

Figure 11. System Specifications tab for a single-stage, subcritical cycle and efficiency-based representation of the compressor

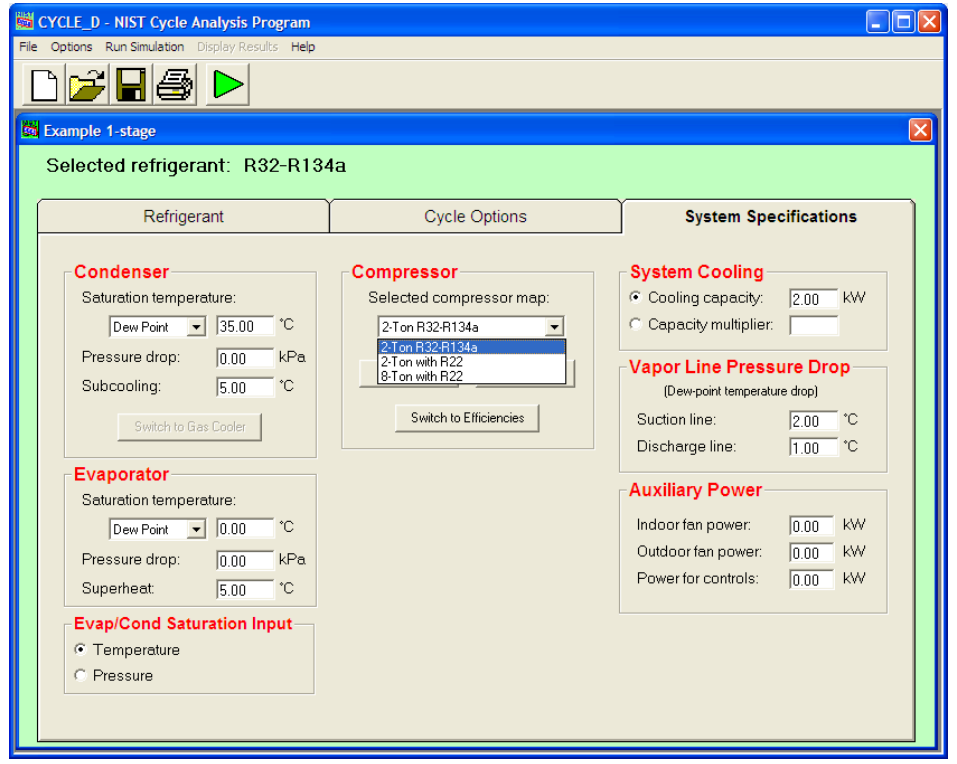

Figure 12. System Specifications tab for a single-stage, subcritical cycle and map-based representation of the compressor

CYCLE_D 17 
Entering Data for the Transcritical Cycle

If the high-side pressure exceeds the critical pressure of the refrigerant, the high-side heat exchanger will operate as a gas cooler. To input data for the gas cooler, click the Switch to Gas Cooler button; a box will appear for specifying the refrigerant temperature at the gas cooler exit, and the option to specify the gas cooler pressure or to have it optimized by CYCLE_D (Figure 13). Simulating a transcritical cycle is available only for single-stage systems using the efficiency-based compressor representation.

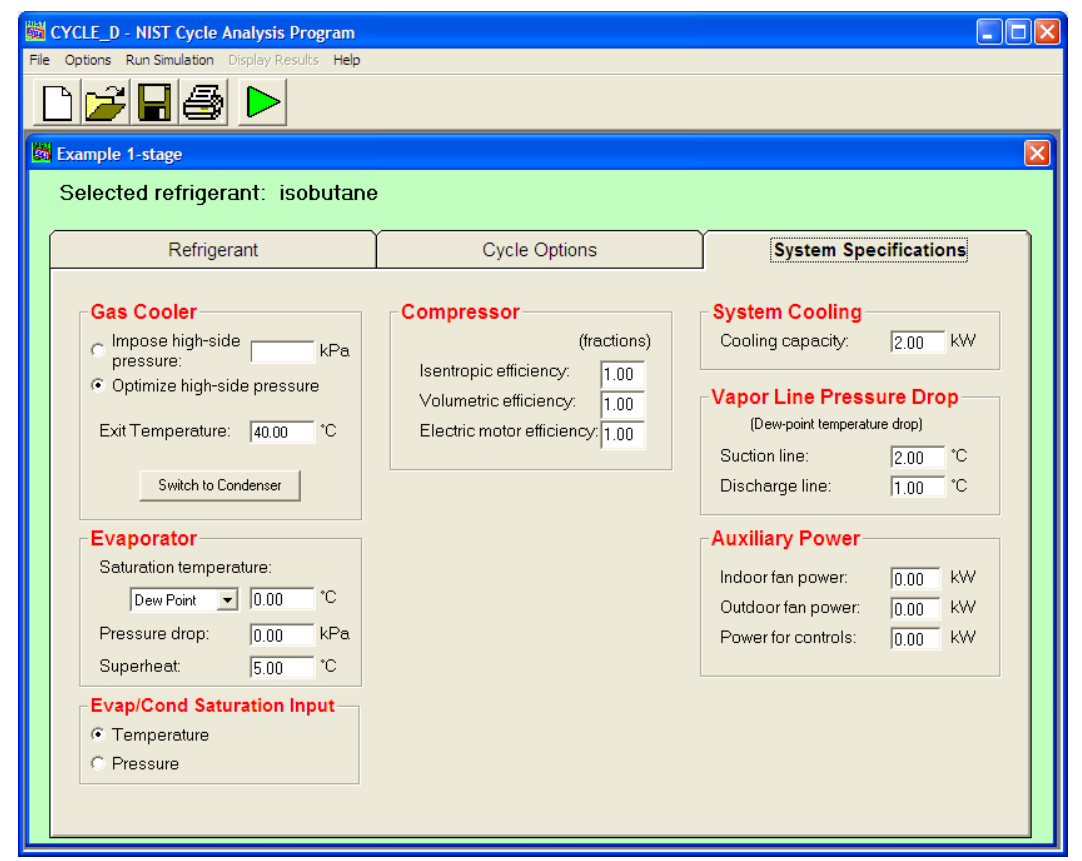

Figure 13. System Specifications tab for a single-stage, transcritical cycle and optimization option selected for the gas cooler pressure

\section{CYCLE_D 18}




\section{Loading an Existing File with Input Data}

Rather than entering data, the user may opt to open a previously stored input data file and modify it. To open an existing file click on the File/Open menu item, or click the Open File button on the power bar. The window shown in Figure 14 will appear. Standard Windows steps are applicable for opening and storing files. After a file is selected and opened, the user should modify the input using different tabs, as explained in the previous section for inputting new data.

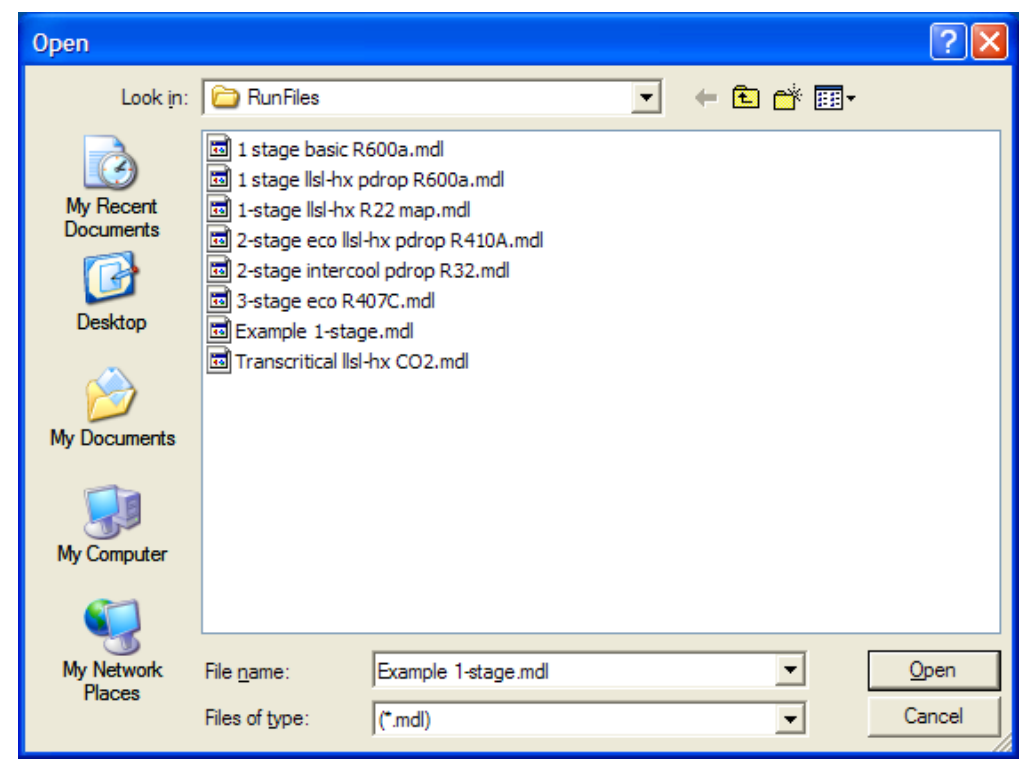

Figure 14. Opening a previously stored input data file

\section{Executing a Simulation Run}

To execute a simulation run, use the Run Simulation pull down menu or click on the Run Simulation button (the green arrow located on the power bar). The program will first perform various checks to ensure that the input data are valid, and then will proceed with the simulation calculations. 


\section{Presenting Simulation Results}

\section{Summary Results}

When the simulation is complete, the Summary Results window will appear. The corresponding windows showing system schematic thermodynamic diagrams and LLSL-HX information can be displayed by using either the Display Results pulldown menu or the four buttons located on the right-hand side of the power bar. Figure 15 shows a tile with the results windows. The window in the front presents Summary Results for the input data shown in Figures 10 and 11. This data set is also contained in the file Example 1-stage.mdl, which the CYCLE_D installation module places in the RunFiles subfolder. Refer to Appendix $\bar{D}$ for the nomenclature.

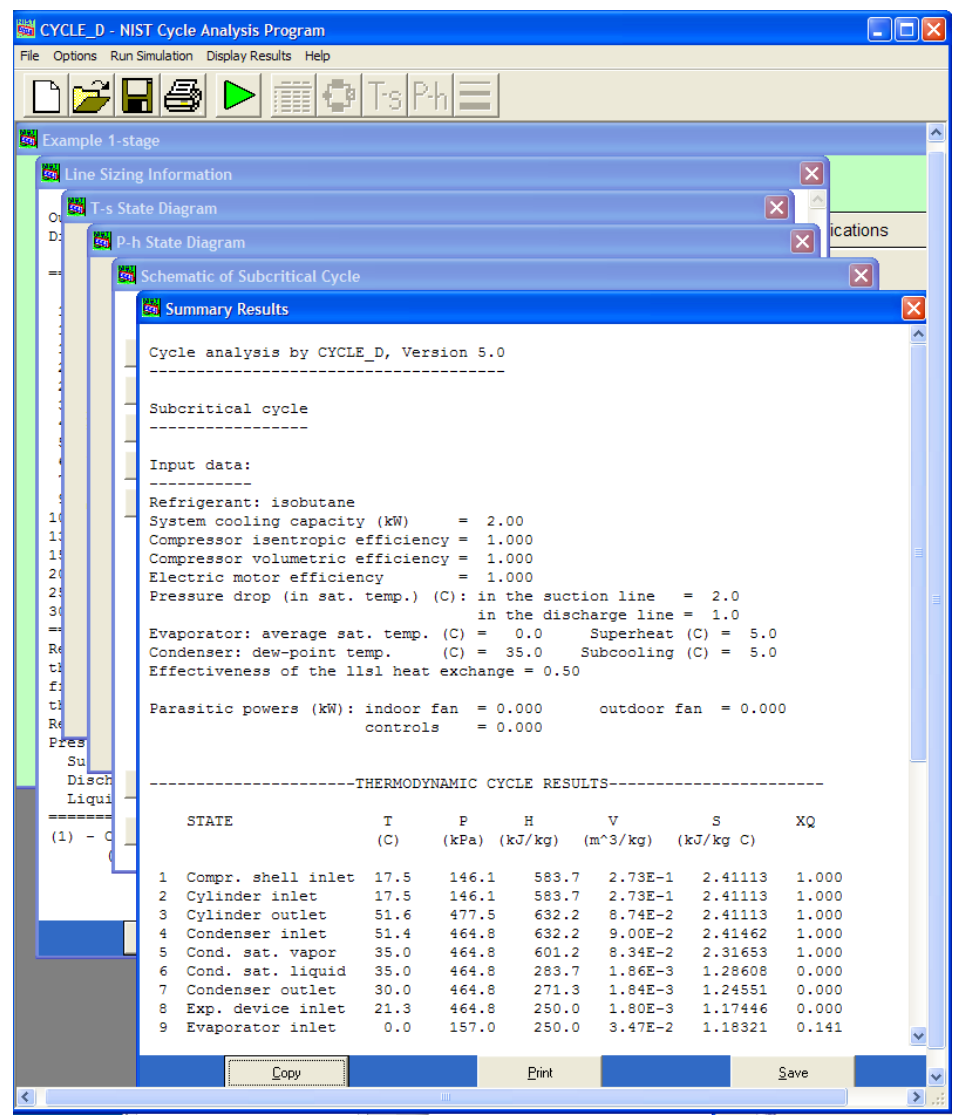

Figure 15. Results windows

\section{CYCLE_D 20}




\section{System Schematic Window}

Figure 16 shows an example System Schematic window with simulation results corresponding to the input data shown in Figures 10 and 11 . To display temperature, pressure, density, enthalpy, or entropy values at the various state points, click on the appropriate control button located on the left side of the screen.

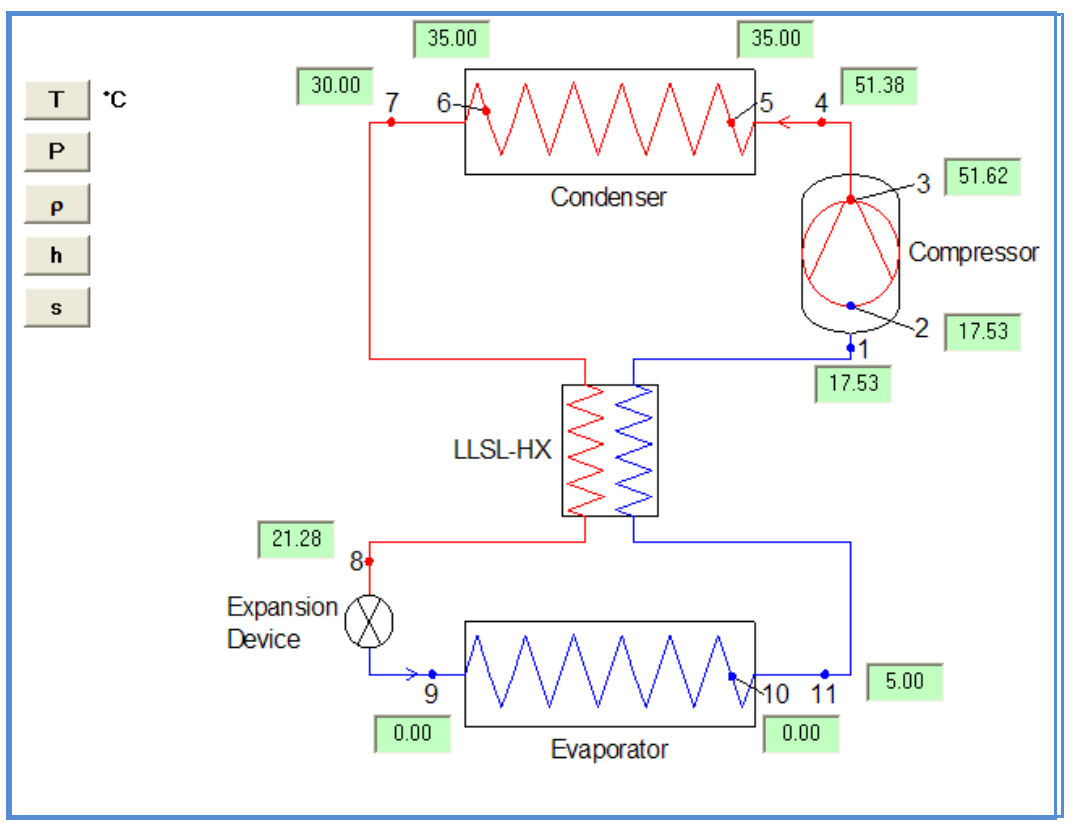

Figure 16. System schematic window

\section{State Diagram Windows}

Figure 17 shows an example P-h State Diagram and Figure 18 shows an example T-s State Diagram corresponding to the input data shown in Figures 10 and 11 . The minimum and maximum tick marks were modified for both figures within CYCLE_D program. To modify (1) the axis labels, (2) the minimum, maximum, and intervals between major tick marks, (3) the font size, (4) the number formatting, (5) the presence or non-presence of gridlines, (6) the specification of the axes in linear or logarithmic scales, and/or (7) the line/symbol type and color for the saturated liquid line, saturated vapor line, or process lines, double-click on the desired figure, after which Figure 18 appears. Note: the P-h State Diagram and the T-s State Diagram have to be modified independently of one another.

CYCLE_D 21 
This publication is available free of charge from http://dx.doi.org/10.6028/NIST.NSRDS.49

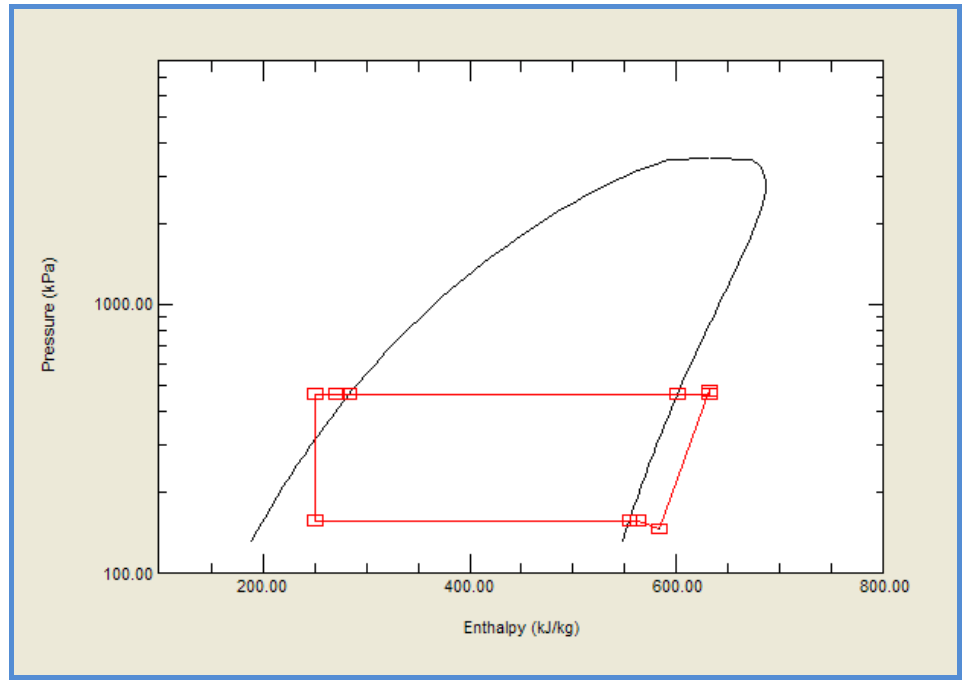

Figure 16. P-h state diagram

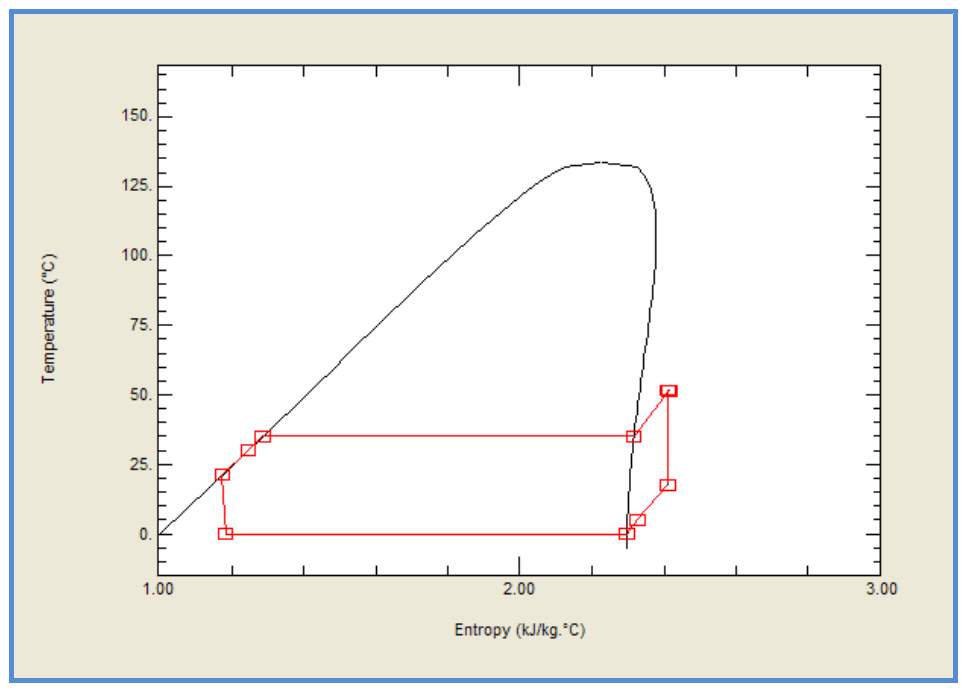

Figure 17. T-s state diagram

\section{CYCLE_D 22}


This publication is available free of charge from http://dx.doi.org/10.6028/NIST.NSRDS.49

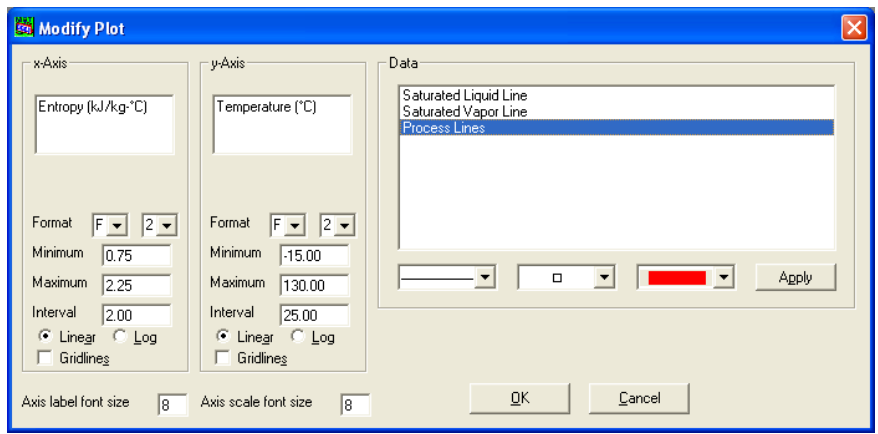

Figure 18. Modifying the P-h or T-s state diagram

\section{Line Sizing Information}

Figure 19 shows the content of the Line Sizing Information window corresponding to the input data shown in Figures 10 and 11.

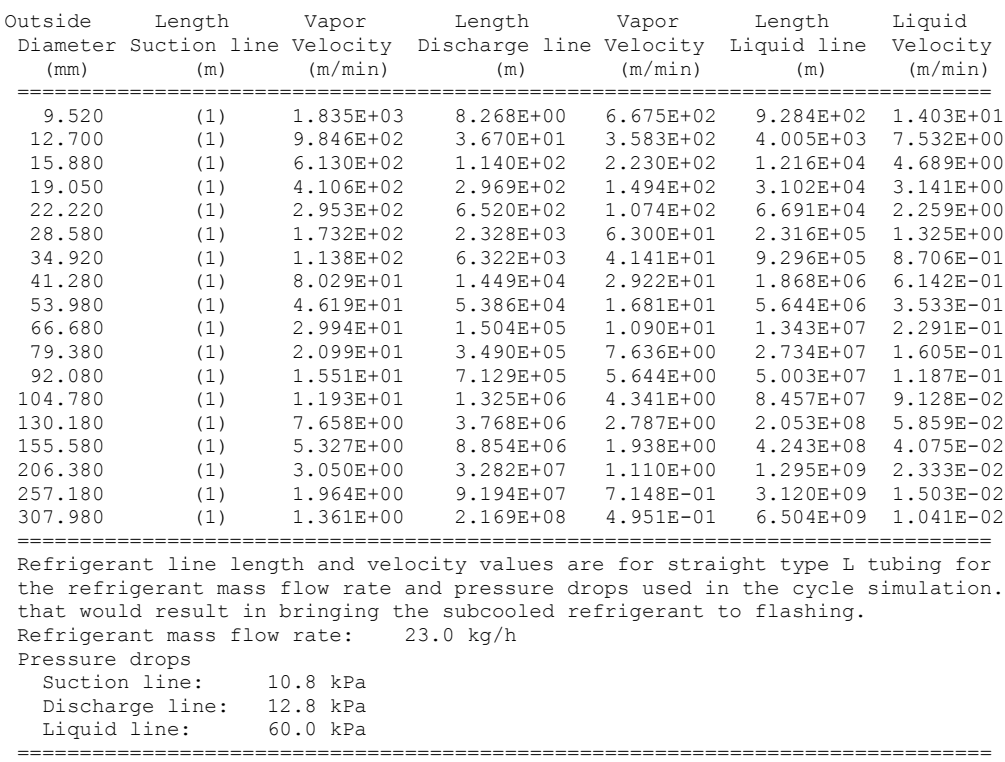

(1) - Calculations are not provided for a non-adiabatic suction line (liquid line/suction line heat exchanger).

Figure 19. Line sizing information 


\section{Saving Input Data}

To save the current input data set, use either the Save button located on the power bar or one of the options available under the File menu item.

\section{Diagnostic Messages}

CYCLE_D provides stable solutions if the specified cycle operating conditions do not extend beyond the range for which REFPROP 9.1 [1] property routines were validated for a particular working fluid (pure refrigerant or refrigerant mixture). If CYCLE_D encounters problems during a cycle simulation, it will write diagnostic messages in the file ERREF.TXT located in the default folder. In such a case, the interface will display a note that the messages were written and will provide the option to read them. Note that refrigerant property routines can become unstable in the neighborhood of the critical point.

\section{Help Menu}

Click on the Help menu item to access online help. The help file consists of two tabs: Index and Search. The Index tab contains detailed help topics arranged alphabetically. The Search tab allows the user to search the contents using keywords. Figure 20 shows a list of help topics in the Index tab.

\section{CYCLE_D 24}


This publication is available free of charge from http://dx.doi.org/10.6028/NIST.NSRDS.49

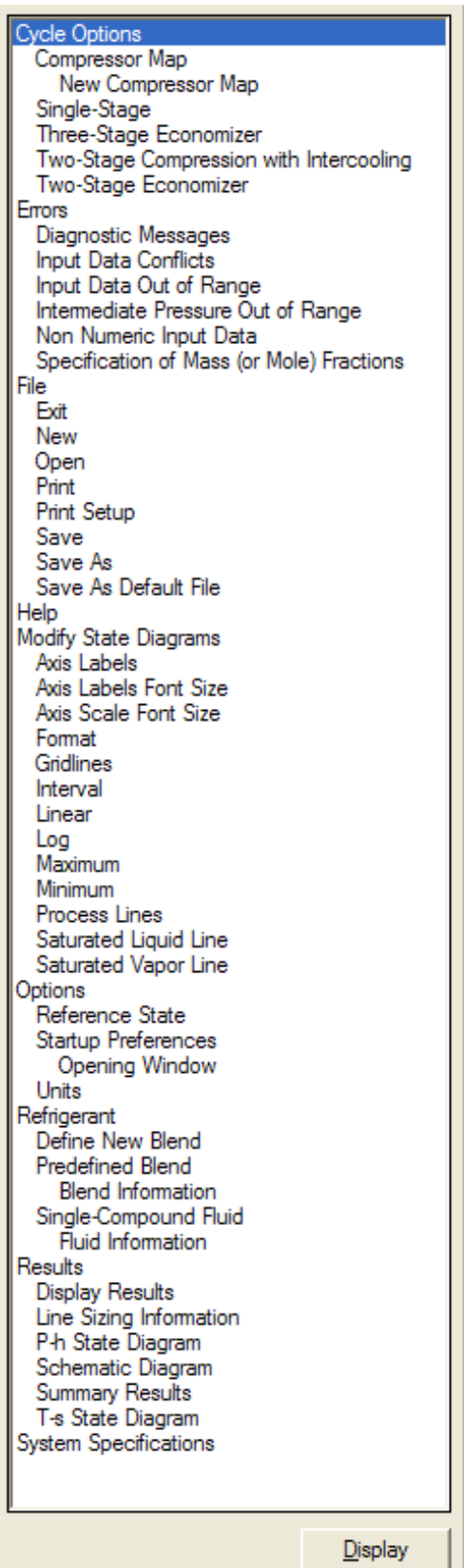

Figure 20. List of help topics in the Help Index tab

CYCLE_D 25 
This publication is available free of charge from http://dx.doi.org/10.6028/NIST.NSRDS.49

\section{REFERENCES}

[1] Lemmon, E. W., Huber, M.L., McLinden, M.O., 2013. NIST Standard Reference Database 23, NIST Reference Fluid Thermodynamic and Transport Properties - REFPROP, Version 9.1. Standard Reference Data Program, National Institute of Standards and Technology, Gaithersburg, MD 20899, U.S.A.

http://www.nist.gov/srd/nist23.cfm.

[2] Performance Rating of Positive Displacement Refrigerant Compressors and Compressor Units, Standard ANSI/AHRI 540-2004. AirConditioning and Refrigeration Institute, Arlington, VA. http://www.ahrinet.org/site/686/Standards/HVACR-IndustryStandards/Search-Standards

[3] White, M.F., 2005. Viscous Fluid Flow, $3^{\text {rd }}$ edition, McGraw-Hill.

[4] Petukhov, B.S, Kurganov, V.A., Gladuntsov, A.I. 1973. Heat transfer in turbulent pipe flow of gases with variable properties. Heat Transfer, Sov. Res., 5, 109-116.

\section{CYCLE_D 26}




\section{Appendix A}

\section{SINGLE-COMPOUND REFRIGERANTS AVAILABLE IN CYCLE_D}

\begin{tabular}{|c|c|c|c|}
\hline Short Name & Full Chemical Name & $\begin{array}{l}\mathrm{T}_{\text {crit }} \\
\left({ }^{\circ} \mathrm{C}\right)\end{array}$ & $\begin{array}{l}\mathbf{T}_{\text {crit }} \\
\left({ }^{\circ} \mathrm{F}\right)\end{array}$ \\
\hline $\mathrm{R}-11$ & trichlorofluoromethane & 198.0 & 388.3 \\
\hline $\mathrm{R}-12$ & dichlorodifluoromethane & 112.0 & 233.6 \\
\hline$R-13$ & chlorotrifluoromethane & 29.2 & 84.6 \\
\hline $\mathrm{R}-13 \mathrm{I} 1$ & trifluoroiodomethane & 123.3 & 253.9 \\
\hline$R-14$ & tetrafluoromethane & -45.6 & -50.2 \\
\hline $\mathrm{R}-21$ & dichlorofluoromethane & 178.3 & 353.0 \\
\hline R-22 & chlorodifluoromethane & 96.2 & 205.1 \\
\hline R-23 & trifluoromethane & 25.9 & 78.7 \\
\hline R-32 & difluoromethane & 78.1 & 172.6 \\
\hline $\mathrm{R}-40$ & methyl chloride & 143.2 & 289.7 \\
\hline $\mathrm{R}-41$ & fluoromethane & 44.1 & 111.4 \\
\hline$R-50$ & methane & -116.7 & -82.7 \\
\hline$R-113$ & 1,1,2-trichloro-1,2,2-trifluoroethane & 214.1 & 417.3 \\
\hline $\mathrm{R}-114$ & 1,2-dichloro-1,1,2,2-tetrafluoroethane & 145.7 & 294.2 \\
\hline$R-115$ & chloropentafluoroethane & 80.0 & 175.9 \\
\hline$R-116$ & hexafluoroethane & 19.9 & 67.8 \\
\hline$R-123$ & 1,1-dichloro-2,2,2-trifluoroethane & 183.7 & 362.6 \\
\hline$R-124$ & 1-chloro-1,2,2,2-tetrafluoroethane & 122.3 & 252.1 \\
\hline$R-125$ & pentafluoroethane & 66.2 & 151.1 \\
\hline$R-134 a$ & 1,1,1,2-tetrafluoroethane & 101.1 & 213.9 \\
\hline$R-141 b$ & 1,1-dichloro-1-fluoroethane & 204.2 & 399.6 \\
\hline$R-142 b$ & 1-chloro-1,1-difluoroethane & 137.1 & 278.8 \\
\hline$R-143 a$ & 1,1,1-trifluoroethane & 72.9 & 163.2 \\
\hline R-152a & 1,1-difluoroethane & 113.3 & 235.9 \\
\hline$R-161$ & fluoroethane & 102.2 & 215.9 \\
\hline $\mathrm{R}-170$ & ethane & 32.2 & 89.9 \\
\hline $\mathrm{R}-218$ & octafluoropropane & 161.5 & 72.0 \\
\hline R-227ea & 1,1,1,2,3,3,3-heptafluoropropane & 102.8 & 217.0 \\
\hline R-236ea & $1,1,1,2,3,3$-hexafluoropropane & 139.3 & 282.7 \\
\hline R-236fa & 1,1,1,3,3,3-hexafluoropropane & 124.9 & 256.9 \\
\hline R-245ca & 1,1,2,2,3-pentafluoropropane & 174.4 & 346.0 \\
\hline$R-245 f a$ & $1,1,1,3,3$-pentafluoropropane & 154.1 & 309.3 \\
\hline $\mathrm{R}-365 \mathrm{mfc}$ & 1,1,1,3,3-pentafluorobutane & 186.9 & 368.3 \\
\hline R-290 & propane & 96.7 & 206.1 \\
\hline R-C318 & octafluorocyclobutane & 115.2 & 239.4 \\
\hline$R-600$ & butane & 152.0 & 305.6 \\
\hline R-600a & isobutane or 2-methylpropane & 134.7 & 274.5 \\
\hline $\mathrm{R}-717$ & ammonia & 132.3 & 270.1 \\
\hline$R-744$ & carbon dioxide & 31.1 & 87.9 \\
\hline $\mathrm{R}-1150$ & ethylene & 9.2 & 48.6 \\
\hline $\mathrm{R}-1216$ & hexafluoropropene & 85.8 & 186.4 \\
\hline$R-1233 z d(E)$ & 1-chloro-3,3,3-trifluoroprop-1-ene & 166.5 & 330.1 \\
\hline$R-1234 y f$ & 2,3,3,3-tetrafluoroprop-1-ene & 94.7 & 202.5 \\
\hline
\end{tabular}

CYCLE_D 27 
This publication is available free of charge from http://dx.doi.org/10.6028/NIST.NSRDS.49

\begin{tabular}{|c|c|c|c|}
\hline Short Name & Full Chemical Name & $\begin{array}{l}\mathrm{T}_{\text {crit }} \\
\left({ }^{\circ} \mathrm{C}\right)\end{array}$ & $\begin{array}{l}\mathrm{T}_{\text {crit }} \\
\left({ }^{\circ} \mathrm{F}\right)\end{array}$ \\
\hline $\mathrm{R}-1234 z e(E)$ & trans-1,3,3,3-tetrafluoropropene & 109.4 & 228 \\
\hline $\mathrm{R}-1234 z e(Z)$ & cis-1,3,3,3-tetrafluoropropene & 150.1 & 302. \\
\hline $\mathrm{R}-1270$ & propylene or propene & 92.4 & 198 \\
\hline R-E143a & methyl-trifluoromethyl-ether & 104.8 & 220. \\
\hline R-E170 & dimethylether (DME) or ethylene oxide & 127.2 & 260. \\
\hline $\mathrm{R}-\mathrm{E} 245 \mathrm{cb} 2$ & methyl-pentafluoroethyl-ether & 133.7 & 272. \\
\hline R-E245fa2 & 2,2,2-trifluoroethyl-difluoromethyl-ether & 171.7 & 341 \\
\hline $\mathrm{R}-\mathrm{E} 347 \mathrm{mcc}$ & methyl-heptafluoropropyl-ether & 164.6 & 328 \\
\hline $\mathrm{CH} 3 \mathrm{CH} 2 \mathrm{CH}=\mathrm{CH} 2$ & 1-butene & 146.1 & 295 \\
\hline Cyclo-C3H6 & cyclo & 125.2 & 257. \\
\hline $\mathrm{C} 2 \mathrm{H} 6 \mathrm{O}$ & r ethyl alcohol & 240.8 & 465 \\
\hline $\mathrm{CH}(\mathrm{CH} 3) 3$ & isobutene or 2-methyl-1-propene & 144.9 & 292. \\
\hline$(\mathrm{CH} 3) 2 \mathrm{CH}(\mathrm{CH} 2) 2 \mathrm{CH} 3$ & isohexane or 2-methylpentane & 224.6 & 436 \\
\hline$(\mathrm{CH} 3)_{2} \mathrm{CHCH} 2 \mathrm{CH} 3$ & isopentane or 2-methylbutane & 187.2 & 369 \\
\hline $\mathrm{CH} 3 \mathrm{OH}$ & methanol & 239.5 & 463. \\
\hline $\mathrm{CH} 3-3(\mathrm{CH} 2)-\mathrm{CH} 3$ & penta & 196.6 & 385. \\
\hline $\mathrm{C} 3 \mathrm{H} 6 \mathrm{O}$ & ace & 235.0 & 454 \\
\hline $\mathrm{C} 4 \mathrm{H} 8$ & ene or cis-2-butene & 162.6 & 324.7 \\
\hline $\mathrm{C} 4 \mathrm{H} 8$ & trans-butene or trans-2-butene & 155.5 & 311 \\
\hline \multirow[t]{2}{*}{ C5F12 } & perfluoropentane or & & \\
\hline & & 147.4 & 297. \\
\hline $\mathrm{C} 5 \mathrm{H} 12$ & ntane or 2,2-dimethylpropane & 160.6 & 321. \\
\hline $\mathrm{C} 6 \mathrm{H} 6$ & benz & 288.9 & 552. \\
\hline $\mathrm{C} 6 \mathrm{H} 12$ & cyclohexane & 280.5 & 536. \\
\hline $\mathrm{C} 6 \mathrm{H} 14$ & hex & 234.7 & 454. \\
\hline $\mathrm{C} 7 \mathrm{H} 16$ & heptane & 267.0 & 512.6 \\
\hline $\mathrm{C} 12 \mathrm{H} 26$ & dodecane & 385.0 & 724.9 \\
\hline SF6 & sulfur hexafluoride & 45.6 & 14.0 \\
\hline
\end{tabular}

The user can add new fluids to CYCLE_D by placing new fluid files into the "fluids" folder. The fluid file must be compatible with REFPROP [1], and its name must start with "R" or "r" (e.g., Rnew2.fld or r754.fld will be recognized by CYCLE_D as fluid files).

\section{CYCLE_D 28}


Appendix B

\section{PREDEFINED REFRIGERANT BLENDS AVAILABLE IN CYCLE_D}

\begin{tabular}{|c|c|c|c|c|}
\hline $\begin{array}{l}\text { ASHRAE } \\
\text { Designation }\end{array}$ & $\begin{array}{l}\text { Composition } \\
\text { Components }\end{array}$ & (mass \%) & $\begin{array}{l}\mathrm{T}_{\text {crit }} \\
\left({ }^{\circ} \mathrm{C}\right)\end{array}$ & $\begin{array}{l}T_{\text {crit }} \\
\left({ }^{\circ} \mathrm{F}\right)\end{array}$ \\
\hline $\mathrm{R}-401 \mathrm{~A}$ & $R-22 / 152 a / 124$ & $53 / 13 / 34$ & 106.9 & 224.3 \\
\hline R-401B & $\mathrm{R}-22 / 152 \mathrm{a} / 124$ & $61 / 11 / 28$ & 104.6 & 220.0 \\
\hline R-401C & $\mathrm{R}-22 / 152 \mathrm{a} / 124$ & $33 / 15 / 52$ & 111.7 & 233.1 \\
\hline R-402A & R-125/290/22 & $60 / 2 / 38$ & 74.8 & 166.6 \\
\hline $\mathrm{R}-402 \mathrm{~B}$ & $R-125 / 290 / 22$ & $38 / 2 / 60$ & 82.1 & 179.7 \\
\hline$R-403 A$ & $\mathrm{R}-290 / 22 / 218$ & $5 / 75 / 20$ & 84.0 & 183.2 \\
\hline$R-403 B$ & R-290/22/218 & $5 / 56 / 39$ & 75.4 & 167.8 \\
\hline $\mathrm{R}-404 \mathrm{~A}$ & $R-125 / 143 a / 134 a$ & $44 / 52 / 4$ & 72.1 & 161.8 \\
\hline$R-405 A$ & $\mathrm{R}-22 / 152 \mathrm{a} / 142 \mathrm{~b} / \mathrm{C} 318$ & $45 / 7 / 5.5 / 42.5$ & 104.3 & 219.8 \\
\hline R-406A & $\mathrm{R}-22 / 600 \mathrm{a} / 142 \mathrm{~b}$ & $55 / 4 / 41$ & 115.5 & 239.8 \\
\hline $\mathrm{R}-407 \mathrm{~A}$ & $\mathrm{R}-32 / 125 / 134 \mathrm{a}$ & $20 / 40 / 40$ & 82.3 & 180.1 \\
\hline R-407B & $R-32 / 125 / 134 a$ & $10 / 70 / 20$ & 74.8 & 166.6 \\
\hline $\mathrm{R}-407 \mathrm{C}$ & $\mathrm{R}-32 / 125 / 134 \mathrm{a}$ & $23 / 25 / 52$ & 86.1 & 187.1 \\
\hline R-407D & $R-32 / 125 / 134 a$ & $15 / 15 / 70$ & 91.6 & 196.9 \\
\hline R-407E & $R-32 / 125 / 134 a$ & $25 / 15 / 60$ & 88.6 & 191.5 \\
\hline R-407F & $\mathrm{R}-32 / 125 / 134 \mathrm{a}$ & $30 / 30 / 40$ & 82.6 & 180.7 \\
\hline$R-408 A$ & $R-125 / 143 a / 22$ & $7 / 46 / 47$ & 82.9 & 181.3 \\
\hline R-409A & $\mathrm{R}-22 / 124 / 142 \mathrm{~b}$ & $60 / 25 / 15$ & 110.1 & 230.1 \\
\hline$R-409 B$ & $R-22 / 124 / 142 b$ & $65 / 25 / 10$ & 107.6 & 225.7 \\
\hline $\mathrm{R}-410 \mathrm{~A}$ & $R-32 / 125$ & $50 / 50$ & 71.3 & 160.4 \\
\hline $\mathrm{R}-410 \mathrm{~B}$ & $\mathrm{R}-32 / 125$ & $45 / 55$ & 70.8 & 159.5 \\
\hline $\mathrm{R}-411 \mathrm{~A}$ & R-1270/22/152a & $1.5 / 87.5 / 11.0$ & 88.9 & 191.9 \\
\hline R-411B & R-1270/22/152a & $3 / 94 / 3$ & 95.7 & 204.2 \\
\hline$R-412 A$ & $\mathrm{R}-22 / 218 / 142 \mathrm{~b}$ & $70 / 5 / 25$ & 107.1 & 224.8 \\
\hline R-413A & $R-218 / 143 a / 600 a$ & $9 / 88 / 3$ & 95.3 & 203.6 \\
\hline$R-414 A$ & $\mathrm{R}-22 / 124 / 600 \mathrm{a} / 142 \mathrm{~b}$ & $51 / 28.5 / 16.5$ & 111.4 & 232.5 \\
\hline R-414B & $\mathrm{R}-22 / 124 / 600 \mathrm{a} / 142 \mathrm{~b}$ & $50 / 39 / 1.5 / 9.5$ & 110.7 & 231.3 \\
\hline$R-415 A$ & $\mathrm{R}-22 / 152 \mathrm{a}$ & $82 / 18$ & 96.7 & 206.0 \\
\hline$R-415 B$ & $\mathrm{R}-22 / 152 \mathrm{a}$ & $25 / 75$ & 109.9 & 229.9 \\
\hline $\mathrm{R}-416 \mathrm{~A}$ & R-124/R134a/600 & $39.5 / 59.0 / 1.5$ & 106.3 & 223.3 \\
\hline $\mathrm{R}-417 \mathrm{~A}$ & R-125/134a/600 & $46.6 / 50.0 / 3.4$ & 85.4 & 185.8 \\
\hline R-417B & R-125/134a/600 & 79.0/18.3/2.7 & 74.1 & 165.3 \\
\hline $\mathrm{R}-417 \mathrm{C}$ & R-125/134a/600 & $19.5 / 78.8 / 1.7$ & 94.6 & 202.2 \\
\hline $\mathrm{R}-418 \mathrm{~A}$ & R-290/22/152a & $1.5 / 96 / 2.5$ & 95.6 & 204.2 \\
\hline R-419A & R-125/134a/DME & $77 / 19 / 4$ & 83.5 & 182.3 \\
\hline $\mathrm{R}-419 \mathrm{~B}$ & R-125/134a/DME & $48.5 / 48 / 3.5$ & 91.1 & 196.0 \\
\hline $\mathrm{R}-420 \mathrm{~A}$ & $R-134 a / 142 b$ & $88 / 12$ & 104.8 & 220.6 \\
\hline $\mathrm{R}-421 \mathrm{~A}$ & R-125/134a & $58 / 42$ & 828 & 181.0 \\
\hline R-421B & R-125/134a & $85 / 15$ & 72.4 & 162.3 \\
\hline$R-422 A$ & R-125/134a/600a & $85.1 / 11.5 / 3.4$ & 70.7 & 159.3 \\
\hline $\mathrm{R}-422 \mathrm{~B}$ & R-125/134a/600a & $55 / 24 / 3$ & 82.0 & 179.6 \\
\hline R-422C & $\mathrm{R}-125 / 134 \mathrm{a} / 600 \mathrm{a}$ & $82 / 15 / 3$ & 72.1 & 161.7 \\
\hline$R-422 D$ & R-125/134a/600a & $65.1 / 31.5 / 3.4$ & 78.2 & 172.8 \\
\hline $\mathrm{R}-422 \mathrm{E}$ & R-125/134a/600a & $58 / 39.3 / 2.7$ & 81.1 & 178.0 \\
\hline$R-423 A$ & R-134a/227ea & $52.5 / 47.5$ & 99.1 & 210.5 \\
\hline
\end{tabular}

CYCLE_D 29 
This publication is available free of charge from http://dx.doi.org/10.6028/NIST.NSRDS.49

\begin{tabular}{|c|c|c|c|c|}
\hline $\begin{array}{l}\text { ASHRAE } \\
\text { Designation }\end{array}$ & $\begin{array}{l}\text { Composition } \\
\text { Components }\end{array}$ & (mass \%) & $\begin{array}{l}\mathrm{T}_{\text {crit }} \\
\left({ }^{\circ} \mathrm{C}\right)\end{array}$ & $\begin{array}{l}T_{\text {crit }} \\
\left({ }^{\circ} \mathrm{F}\right)\end{array}$ \\
\hline$R-424 A$ & R-125/134a/600a/600/601a & $50.5 / 47 / 0.9 / 1 / 0.6$ & 84.7 & 184 \\
\hline$R-425 A$ & R-32/134a/227ea & $18.5 / 69.5 / 12$ & 93.9 & 10 \\
\hline $\mathrm{R}-426 \mathrm{~A}$ & R-125/134a/600/601a & $5.1 / 93 / 1.3 / 0.6$ & 99.0 & 210 . \\
\hline R-427A & R-32/125/143a/134a & $15 / 25 / 10 / 50$ & 85.5 & 185 \\
\hline $\mathrm{R}-428 \mathrm{~A}$ & R-125/143a/290/600a & $77.5 / 20 / 0.6 / 1.9$ & 68.0 & \\
\hline R-429A & $\mathrm{DME} / 152 \mathrm{a} / 600 \mathrm{a}$ & $60 / 10 / 30$ & 122.0 & 251 \\
\hline $\mathrm{R}-430 \mathrm{~A}$ & R-152a/600a & $76 / 24$ & 107.0 & 224 \\
\hline $\mathrm{R}-431 \mathrm{~A}$ & $R-290 / 152 a$ & $71 / 29$ & 91.8 & 197. \\
\hline$R-432 A$ & R-1270/DME & $80 / 20$ & 97.3 & 207 \\
\hline R-433A & $R-1270 / 290$ & $30 / 70$ & 94.4 & 201 \\
\hline R-433B & $R-1270 / 290$ & $5 / 95$ & 96.3 & 205 \\
\hline R-433C & R-1270/290 & $25 / 75$ & 94.8 & 202. \\
\hline$R-434 A$ & R-125/143a/134a/600a & $63.2 / 18 / 16 / 2.8$ & 74.1 & 165. \\
\hline$R-435 A$ & $\mathrm{DME} / \mathrm{R}-152 \mathrm{a}$ & $80 / 20$ & 123.1 & 253 \\
\hline R-436A & R-290/600a & $56 / 44$ & 115.9 & 240 \\
\hline$R-436 B$ & R-290/600a & $52 / 48$ & 117.4 & 243. \\
\hline $\mathrm{R}-437 \mathrm{~A}$ & $R-125 / 134 a / 600 / 601 a$ & 19.5/78.5/1.4/0.6 & 95.5 & 203. \\
\hline$R-438 A$ & R-32/125/134a/600/601a & $8.5 / 45 / 44.2 / 1.7 / 0.6$ & 83.8 & 182 \\
\hline $\mathrm{R}-439 \mathrm{~A}$ & $\mathrm{R}-32 / 125 / 600 \mathrm{a}$ & $50 / 47 / 3$ & 70.3 & 158 \\
\hline $\mathrm{R}-440 \mathrm{~A}$ & $34 a / 152 a$ & /97.8 & 112.7 & 234 \\
\hline R-441A & $\mathrm{R}-170 / 290 / 600 \mathrm{a} / 600$ & $3 / 5$ & 118.5 & 245. \\
\hline $\mathrm{R}-442 \mathrm{~A}$ & R-32/125/134a/152a/227ea & $31 / 31 / 30 / 3 / 5$ & 82.1 & 179 \\
\hline$R-443 A$ & R-1270/290/600a & $55 / 40 / 5$ & 96.0 & 204. \\
\hline $\mathrm{R}-444 \mathrm{~A}$ & $\mathrm{R}-32 / 152 \mathrm{a} / 1234 z e(E)$ & $12 / 5 / 83$ & 106.3 & 223. \\
\hline R-444B & $\mathrm{R}-32 / 152 \mathrm{a} / 1234 \mathrm{ze}(\mathrm{E})$ & $41.5 / 10 / 48.5$ & 95.7 & 204.2 \\
\hline R-445A & R-744/134a/1234ze(E) & $6 / 9 / 85$ & 106.1 & 222.9 \\
\hline $\mathrm{R}-446 \mathrm{~A}$ & $\mathrm{R}-32 / 1234 z e(E) / 600$ & $68 / 29 / 3$ & 86.1 & 186. \\
\hline $\mathrm{R}-447 \mathrm{~A}$ & $\mathrm{R}-32 / 125 / 1234 \mathrm{ze}(\mathrm{E})$ & $68 / 3.5 / 28.5$ & 85.3 & 185 \\
\hline \multirow[t]{2}{*}{$\mathrm{R}-448 \mathrm{~A}$} & \multicolumn{4}{|c|}{$\mathrm{R}-32 / 125 / 1234 \mathrm{yf} / 134 \mathrm{a} / 1234 \mathrm{ze}(\mathrm{E})$} \\
\hline & & $26 / 26 / 20 / 21 / 7$ & 82.7 & 180. \\
\hline R-449A & 134a & 24.3/24.7/25.3/25.7 & 82.1 & 179. \\
\hline$R-449 B$ & R-32/125/1234yf/134a & $25 / 24 / 23 / 27$ & 82.2 & 180 \\
\hline R-450A & $R-134 a / 1234 z e(E)$ & $42 / 58$ & 104.5 & 220 \\
\hline$R-451 \mathrm{~A}$ & $\mathrm{R}-1$ & 89. & 94.4 & 201. \\
\hline $\mathrm{R}-451 \mathrm{~B}$ & -yf/134a & 88.8 & 94.3 & $201 . \varepsilon$ \\
\hline R-452A & R-32/125/1234yf & $11 / 59 / 30$ & 75.1 & 167.1 \\
\hline R-452B & $\mathrm{R}-32 / 125 / 1234 \mathrm{yf}$ & $67 / 7 / 26$ & 77.1 & 170.8 \\
\hline R-454A & $\mathrm{R}-32 / 1$ & $35 / 65$ & 81.7 & 179. \\
\hline R-454B & $\mathrm{R}-32$ & $69 / 31$ & 78.1 & 172.6 \\
\hline $\mathrm{R}-454 \mathrm{C}$ & R-32/1234yf & $21.5 / 78.5$ & 79.3 & 174.7 \\
\hline $\mathrm{R}-500$ & $\mathrm{R}-12 / 152 \mathrm{a}$ & $73.8 / 26.2$ & 102.1 & 215. \\
\hline R-501 & $\mathrm{R}-22 / 12$ & $75 / 25$ & 95.9 & 204.5 \\
\hline $\mathrm{R}-502$ & $\mathrm{R}-22 / 115$ & $48.8 / 5$ & 81.5 & 178. \\
\hline R-503 & $\mathrm{R}-2$ & 40. & 18.3 & 64. \\
\hline $\mathrm{R}-504$ & $\mathrm{R}-32 / 115$ & $48.2 / 51.8$ & 62.2 & 144.0 \\
\hline $\mathrm{R}-507 \mathrm{~A}$ & $\mathrm{R}-125 / 143 \mathrm{a}$ & $50 / 50$ & 70.6 & 159.1 \\
\hline$R-508 A$ & $\mathrm{R}-23 / 116$ & $39 / 61$ & 10.2 & 50.3 \\
\hline$R-508 B$ & $\mathrm{R}-23 / 116$ & $46 / 54$ & 11.2 & 52. \\
\hline R-509A & $\mathrm{R}-22 / 218$ & $44 / 56$ & 68.5 & 155.2 \\
\hline$R-510 A$ & $\mathrm{DME} / 600 \mathrm{a}$ & $88 / 12$ & 125.7 & 258.2 \\
\hline R-511A & R-290/DME & $95 / 5$ & 97.0 & 206.6 \\
\hline$R-512 A$ & $R-134 a / 152 a$ & $5 / 9$ & 112.8 & \\
\hline R-513A & $R-1234 y f / 134 a$ & $56 / 44$ & 94.9 & 202.8 \\
\hline
\end{tabular}

\section{CYCLE_D 30}




\section{Appendix C}

\section{COMPRESSOR MAPS}

\section{Compressor Map Formats}

CYCLE_D uses three types of compressor maps for representing the compressor performance. Their format is give below.

Compressor map \# 1 (based on the ANSI/AHRI Standard 540 [2])

$\mathrm{X}=\mathrm{B} 1+\mathrm{B} 2 \cdot \mathrm{T}_{\mathrm{S}}+\mathrm{B} 3 \cdot \mathrm{T}_{\mathrm{d}}+\mathrm{B} 4 \cdot \mathrm{T}_{\mathrm{s}}^{2}+\mathrm{B} 5 \cdot \mathrm{T}_{\mathrm{s}} \cdot \mathrm{T}_{\mathrm{d}}+\mathrm{B} 6 \cdot \mathrm{T}_{\mathrm{d}^{2}}+$ $B 7 \cdot T_{s}{ }^{3}+B 8 \cdot T_{d} \cdot T_{s}{ }^{2}+B 9 \cdot T_{S} \cdot T_{d}{ }^{2}+B 10 \cdot T_{d}{ }^{3}$

where

$\mathrm{B} 1-\mathrm{B} 10=$ correlation coefficients

$\mathrm{T}_{\mathrm{S}} \quad=$ compressor suction dew-point temperature, ${ }^{\circ} \mathrm{C}\left({ }^{\circ} \mathrm{F}\right)$

$\mathrm{T}_{\mathrm{d}} \quad=$ compressor discharge dew-point temperature, ${ }^{\circ} \mathrm{C}\left({ }^{\circ} \mathrm{F}\right)$

$\mathrm{X}=$ represents (as designated): refrigerant mass flow rate, $\mathrm{kg} / \mathrm{s}$ (lb/h) or power input W, (W)

Compressor map \# 2 (pressure-based correlation)

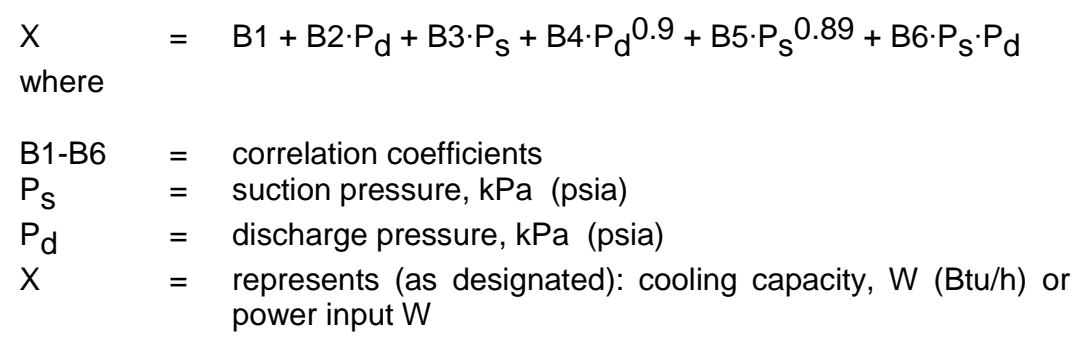

Compressor map \# 3 (modified temperature-based correlation)
$\mathrm{X}=\mathrm{B} 1+\mathrm{B} 2 \cdot \mathrm{T}_{\mathrm{d}}+\mathrm{B} 3 \cdot \mathrm{T}_{d^{2}}+\mathrm{B} 4 \cdot \mathrm{T}_{\mathrm{S}}+\mathrm{B} 5 \cdot \mathrm{T}_{\mathrm{s}} \cdot \mathrm{T}_{d}+\mathrm{B} 6 \cdot \mathrm{T}_{\mathrm{S}} \cdot \mathrm{T}_{\mathrm{d}^{2}+}$ $B 7 \cdot T_{s}{ }^{2}+B 8 \cdot T_{d} \cdot T_{s}{ }^{2}+B 9 \cdot T_{s}{ }^{2} \cdot T_{d}{ }^{2}$
where
B1-B9 $=$ correlation coefficients
$\mathrm{T}_{\mathrm{S}} \quad=$ compressor suction dew-point temperature, ${ }^{\circ} \mathrm{C}\left({ }^{\circ} \mathrm{F}\right)$
$\mathrm{T}_{\mathrm{d}} \quad=$ compressor discharge dew-point temperature, ${ }^{\circ} \mathrm{C}\left({ }^{\circ} \mathrm{F}\right)$
$\mathrm{X}=$ represents (as designated): cooling capacity, $\mathrm{W}(\mathrm{Btu} / \mathrm{h})$ or power input kW




\section{Preparing a New Compressor Map}

In the System Specifications tab, click the Switch to Maps button, and then click the Create New button shown in Figure $\mathrm{C} 1$.

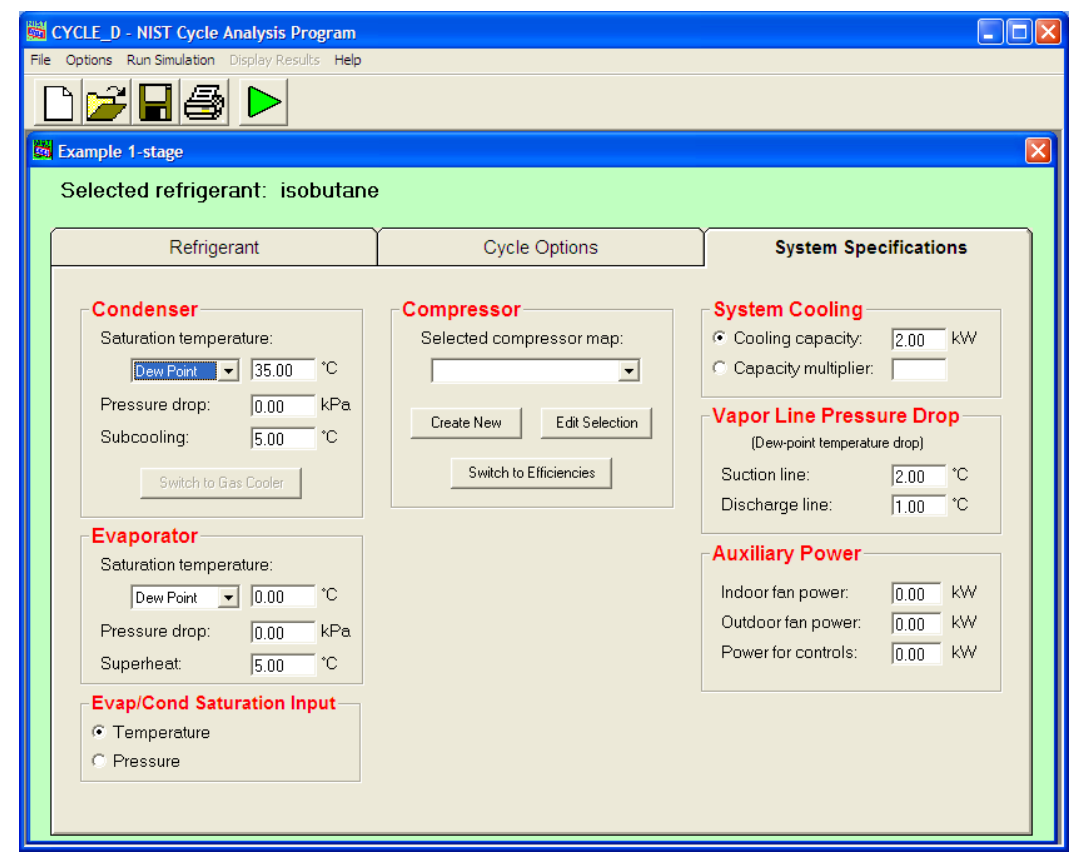

Figure C1. System Specifications tab showing the Create New and Edit Selection compressor map options after a click on the Switch to Maps button

Click the Create New to have the input window displayed for compressor maps (Figure C2). The window has radio buttons for selecting one of the three compressor maps and their units. The units selected in the window are applicable to the compressor map output, coefficients and temperature unit for which the coefficients were developed. This unit selection does not override the units the user selected outside of this window for the input data and output of simulation results.

The refrigerant selection in this window will override the prior selection of the refrigerant within the Refrigerant tab (Figure 1). The refrigerants available for selection in this window are those available

\section{CYCLE_D 32}


within the Refrigerant tab as Single-Compound Fluid or Predefined Blend. If the compressor uses a blend that is not available, the user needs to define this blend first using the Define New Blend (Figure 1) button before inputting compressor coefficients.

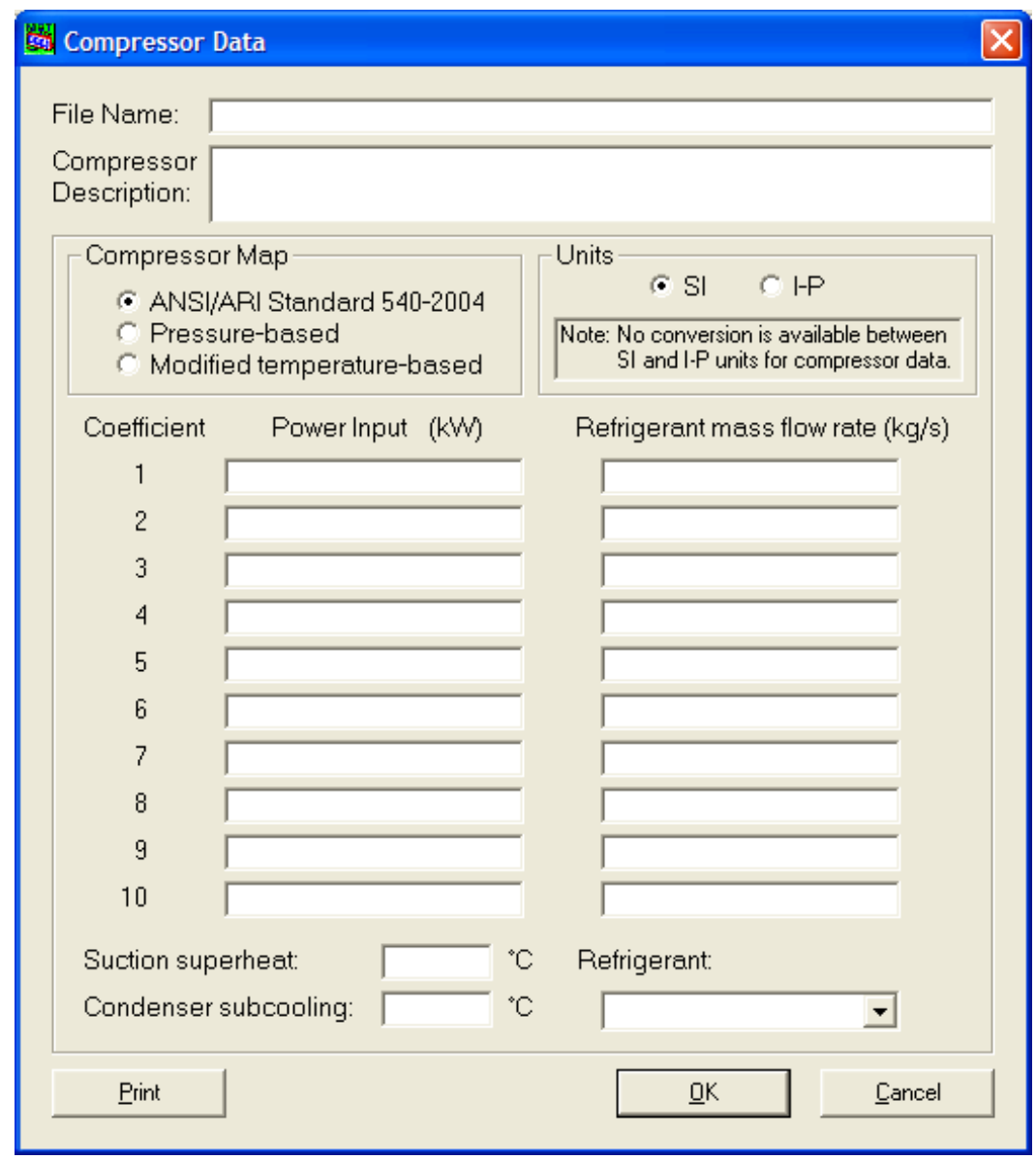

Figure C2. Input data window for compressor map data (ANSI/AHRI Standard 540-2004 map selected) 


\section{Appendix D}

\section{NOMENCLATURE USED FOR REPORTING SIMULATION RESULTS}

This appendix presents the symbol convention used for simulation results in the order they appear on the printout. Self-explanatory output is omitted here. Note that the printout varies somewhat between simulation options.

\section{Thermodynamic Cycle Results}

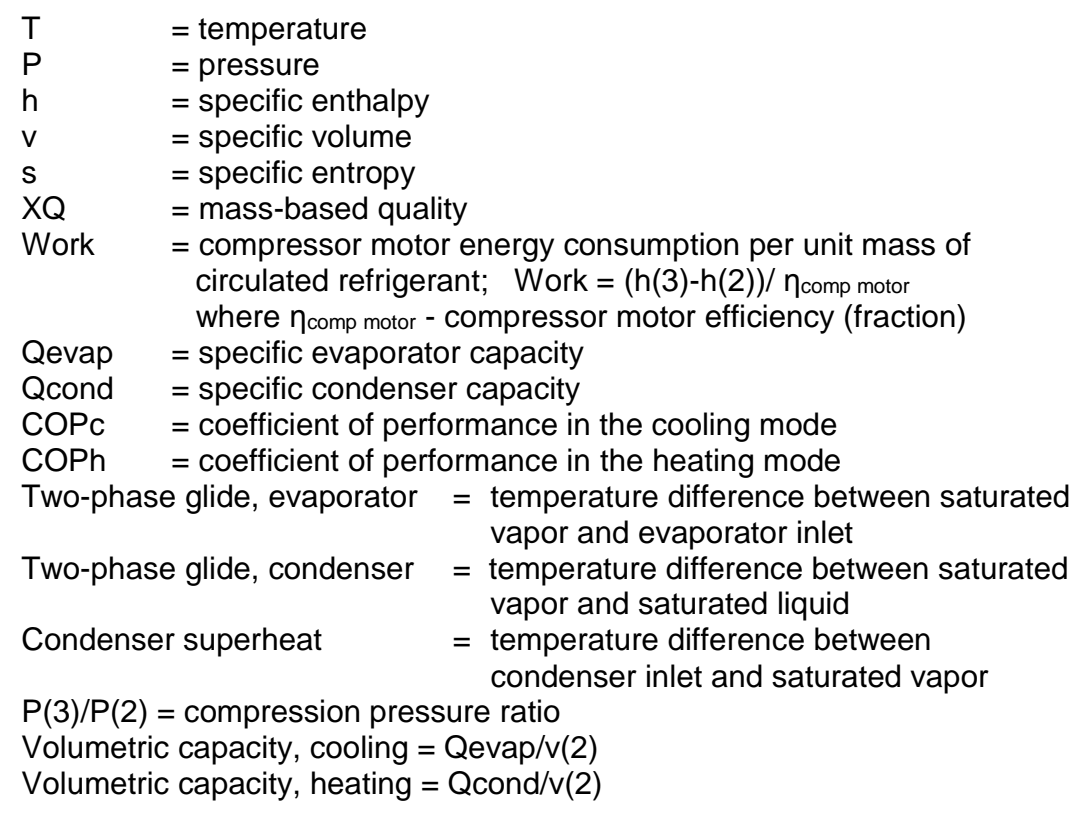

\section{Compressor and System Results}

$\begin{array}{ll}\mathrm{m}^{\wedge} 3 / \mathrm{h} \text { or } \mathrm{cfm} & \text { compressor volumetric output } \\ \mathrm{m}^{\wedge} 3 / \mathrm{h} / \mathrm{kW} \text { or cfm/ton }= & \text { (compressor volumetric output) } /(\text { cooling capacity } \\ & \text { of evaporator }\{1 \text { ton }=12000 \mathrm{Btu} / \mathrm{h}\} \\ = & \text { sum of powers of compressor, indoor fan, outdoor } \\ & \text { fan, and controls } \\ \text { Total power } & =(\text { system cooling capacity }) /(\text { total power }) \\ \text { COPc,sys } & =(\text { system heating capacity }) /(\text { total power })\end{array}$

\section{CYCLE_D 34}




\section{Appendix E}

\section{UNITS, CHECKS AND WARNINGS}

There are a number of built-in checks and warnings in CYCLE_D. Efforts have been made in developing the system to make the checks selfexplanatory. Presented below are: (1) an explanation of consistency in units and (2) some examples of the run time checks and warnings.

\section{(1) Systems of Units}

Users may select either I-P or SI units.

\section{I-P Units:}

By selecting "I-P units," temperatures are entered in ${ }^{\circ} \mathbf{F}$.

\section{SI Units:}

By selecting "SI units," temperatures are entered in ${ }^{\circ} \mathbf{C}(\mathbf{S I}-$ Celsius option) or K (SI - Kelvin option).

\section{Common Bases:}

In both systems, mass composition and efficiency values are entered as decimals not greater than unity. (Note, decimals, not percentages)

\section{(2) Checks and Warnings}

The following are examples of checks and warnings built into the CYCLE_D system:

1. In selecting the number of refrigerants in a new mixture, the number must be from 2 to 5 .

2. If the sum of refrigerant mass (or mole) fractions is greater than unity, an error message is issued.

3. Compressor isentropic efficiency values must be greater than or equal to 0.05 and less than or equal to unity.

4. Compressor volumetric efficiency values must be greater than or equal to 0.05 and less than or equal to unity.

CYCLE_D 35 
5. Compressor motor efficiency values must be greater than or equal to 0.05 and less than or equal to unity.

6. The evaporator saturation temperature drop specification is unrealistic.

7. The bubble-point temperature (or pressure) of refrigerant in the condenser must be greater than the dew-point temperature (or pressure) of refrigerant in the evaporator.

8. The condenser temperature (or pressure) must be greater than the evaporator temperature (or pressure).

9. The condenser saturation temperature (or pressure) must be less than the refrigerant critical temperature (or pressure).

10. The gas cooler refrigerant pressure must be greater than the critical pressure.

11. The intermediate pressures for the two-stage economizer cycle, the two-stage compression with intercooling cycle, and the three-stage economizer cycle must fall between the evaporator and condenser pressures.

12. For the three-stage economizer cycle, the intermediate pressure of the low-pressure stage must be below the intermediate pressure of the high-pressure stage.

\section{CYCLE_D 36}


This publication is available free of charge from http://dx.doi.org/10.6028/NIST.NSRDS.49

\title{
Appendix F
}

\section{CONTACTS}

If you have comments or questions about the database, the Standard Reference Data Program would like to hear from you. Also, if you should have any problems with the CDs or installation, please let us know by contacting:

\author{
Cindy McKneely \\ National Institute of Standards and Technology \\ Office of Data Informatics (ODI) \\ 100 Bureau Drive, MS 8550 \\ Gaithersburg, MD 20899-8550 \\ Phone: $301-975-4332$ \\ E-mail: data@nist.gov
}

If you have questions or problems pertaining to the use of CYCLE_D, contact:

Piotr A. Domanski

National Institute of Standards and Technology

Engineering Laboratory

100 Bureau Drive, MS 8631

Gaithersburg, MD 20899-8631

E-mail: piotr.domanski@nist.gov 